Prepared In Cooperation with the National Park Service

\title{
Provisional Maps of Thermal Areas in Yellowstone National Park, based on Satellite Thermal Infrared Imaging and Field Observations
}

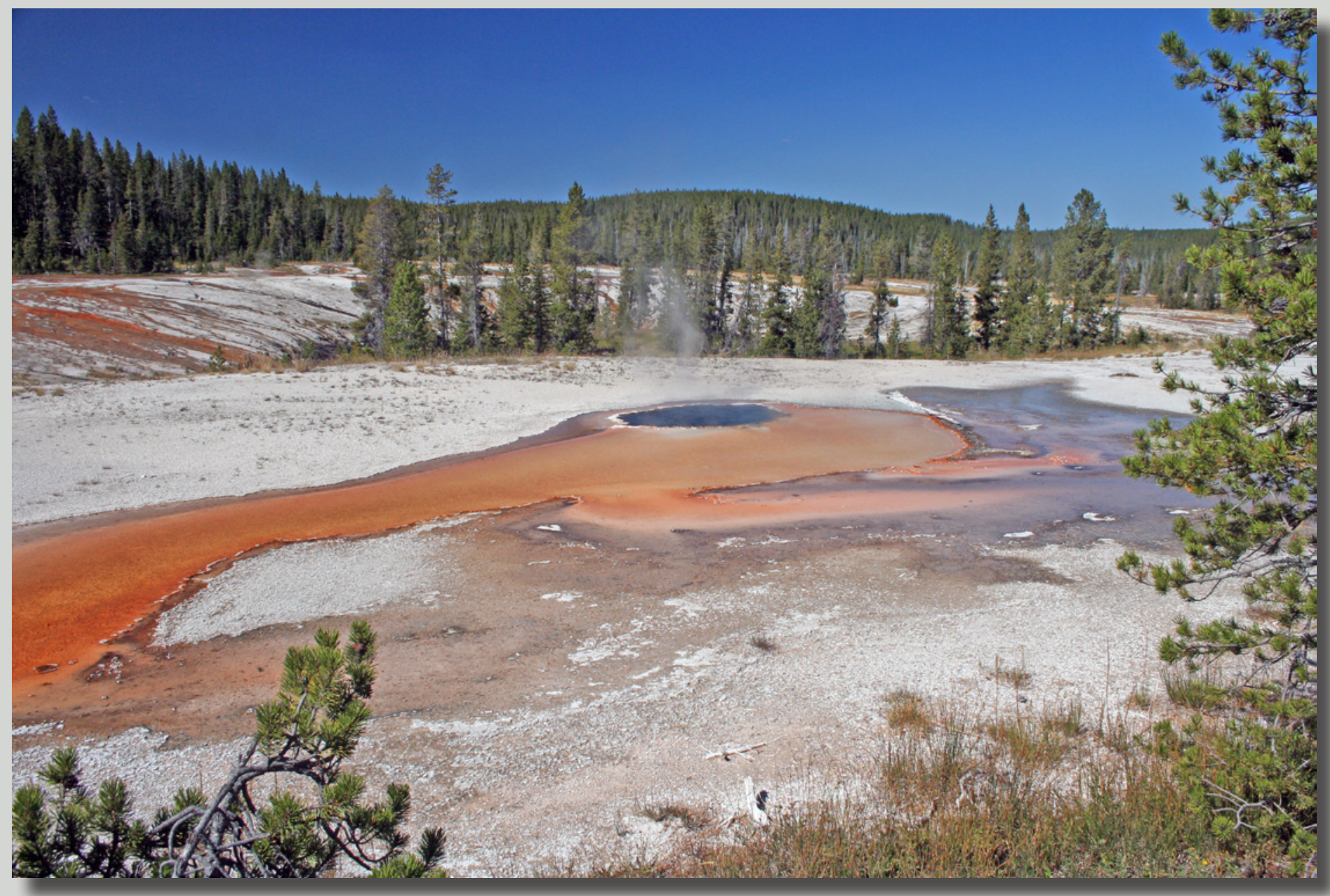

Scientific Investigations Report 2014-5137 
Cover Photograph:

Shoshone Geyser Basin, Yellowstone National Park, Wyoming. Photograph by R. Greg Vaughan. 


\section{Provisional Maps of Thermal Areas in Yellowstone National Park, based on Satellite Thermal Infrared Imaging and Field Observations}

By R. Greg Vaughan, Henry Heasler, Cheryl Jaworowski, Jacob B. Lowenstern, and Laszlo P. Keszthelyi

Prepared In Cooperation with the National Park Service

Scientific Investigations Report 2014-5137 


\title{
U.S. Department of the Interior SALLY JEWELL, Secretary
}

\section{U.S. Geological Survey Suzette M. Kimball, Acting Director}

\author{
U.S. Geological Survey, Reston, Virginia: 2014
}

For more information on the USGS - the Federal source for science about the Earth, its natural and living resources, natural hazards, and the environment-visit http://www.usgs.gov or call 1-888-ASK-USGS

For an overview of USGS information products, including maps, imagery, and publications, visit http://www.usgs.gov/pubprod

To order this and other USGS information products, visit http://store.usgs.gov

Suggested citation:

Vaughan, R.G., Heasler, H., Jaworowski, C., Lowenstern, J.B., and Keszthelyi, L.P., 2013, Provisional maps of thermal areas in Yellowstone National Park, based on satellite thermal infrared imaging and field observations: U.S. Geological Survey Scientific Investigations Report 2014-5137, 22 p., http://dx.doi.org/10.3133/sir20145137.

Any use of trade, firm, or product names is for descriptive purposes only and does not imply endorsement by the U.S. Government.

Although this information product, for the most part, is in the public domain, it also may contain copyrighted materials as noted in the text. Permission to reproduce copyrighted items must be secured from the copyright owner.

ISSN: 2328-0328 (online) 


\section{Acknowledgments}

The research described here was carried out at the U.S. Geological Survey (USGS) Astrogeology Science Center in Flagstaff, Arizona, with support from the USGS Mendenhall Postdoctoral Research Program, the USGS Volcano Hazards Program, and the NASA ROSES New Investigator Program. Many thanks to Trent Hare, Shaul Hurwitz, Fred Kruse, Candi Kruse, Betsy Littlefield, Dan Mahony, Leon Maldonado, Lisa Morgan, Pat Shanks, Angie van Patten, Richard Vaughan, and Rick Wessels.

\section{Contents}

Abstract
Introduction.
Terminology
Data
Data Processing and Interpretation
ASTER Thermal Pixel Mapping
GSTER TIR Background Subtraction
Discussion
Summary and Conclusions
Discussion
Database Contents
Vector Data
Datasets Not Included in this Release

\section{Figures}

1. Map of Yellowstone National Park showing location of thermal areas........................................

2. Map of Yellowstone National Park overlaying aerial orthophotography...................................5

3. Map of Yellowstone National Park showing Research Coordination Network thermal

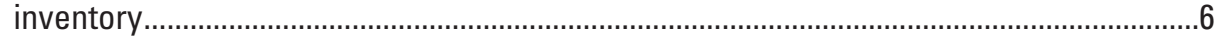

4. Imagery showing geometric adjustment of thermal infrared data .............................................

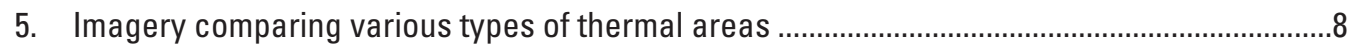

6. Maps and photographs of Shoshone Geyser Basin and Shoshone Creek thermal drainage...9

7. Imagery and histogram of nighttime temperatures at Heart Lake Geyser Basin .....................11

8. Maps comparing thermal area polygons and thermal pixel polygons .....................................13

9. Maps showing thermal anomalies in the region around Sulfur Hills and Turbid Lake .............15 


\section{Tables}

1. Analysis of Heart Lake Geyser Basin thermal infrared data...................................................11

A1. Names and characteristics of Yellowstone's thermal areas. 


\section{Conversion Factors}

SI to Inch/Pound

\begin{tabular}{lcl}
\hline \multicolumn{1}{c}{ Multiply } & \multicolumn{1}{c}{ By } & To obtain \\
\hline \multicolumn{3}{c}{ Length } \\
\hline centimeter $(\mathrm{cm})$ & 0.3937 & inch (in.) \\
millimeter $(\mathrm{mm})$ & 0.03937 & inch (in.) \\
meter $(\mathrm{m})$ & 3.281 & foot (ft) \\
kilometer $(\mathrm{km})$ & 0.6214 & mile (mi) \\
meter $(\mathrm{m})$ & 1.094 & yard (yd) \\
\hline \multicolumn{3}{c}{ Area } \\
\hline square meter $\left(\mathrm{m}^{2}\right)$ & 0.0002471 & acre \\
square kilometer $\left(\mathrm{km}^{2}\right)$ & 247.1 & acre \\
square meter $\left(\mathrm{m}^{2}\right)$ & 10.76 & square foot $\left(\mathrm{ft}^{2}\right)$ \\
square kilometer $\left(\mathrm{km}^{2}\right)$ & 0.3861 & square mile $\left(\mathrm{mi}^{2}\right)$ \\
\hline
\end{tabular}

Temperature in degrees Celsius $\left({ }^{\circ} \mathrm{C}\right)$ may be converted to degrees Fahrenheit $\left({ }^{\circ} \mathrm{F}\right)$ as follows:

${ }^{\circ} \mathrm{F}=\left(1.8 \times{ }^{\circ} \mathrm{C}\right)+32$

Horizontal coordinate information is referenced to the North American Datum of 1983 (NAD 83).

Altitude, as used in this report, refers to distance above the vertical datum. 



\title{
Provisional Maps of Thermal Areas in Yellowstone National Park, based on Satellite Thermal Infrared Imaging and Field Observations
}

\author{
By R. Greg Vaughan', Henry Heasler², Cheryl Jaworowski², Jacob B. Lowenstern', and Laszlo P. Keszthelyi ${ }^{1}$
}

\section{Abstract}

Maps that define the current distribution of geothermally heated ground are useful toward setting a baseline for thermal activity to better detect and understand future anomalous hydrothermal and (or) volcanic activity. Monitoring changes in the dynamic thermal areas also supports decisions regarding the development of Yellowstone National Park infrastructure, preservation and protection of park resources, and ensuring visitor safety. Because of the challenges associated with field-based monitoring of a large, complex geothermal system that is spread out over a large and remote area, satellite-based thermal infrared images from the Advanced Spaceborne Thermal Emission and Reflection Radiometer (ASTER) were used to map the location and spatial extent of active thermal areas, to generate thermal anomaly maps, and to quantify the radiative component of the total geothermal heat flux. ASTER thermal infrared data acquired during winter nights were used to minimize the contribution of solar heating of the surface. The ASTER thermal infrared mapping results were compared to maps of thermal areas based on field investigations and highresolution aerial photos. Field validation of the ASTER thermal mapping is an ongoing task. The purpose of this report is to make available ASTER-based maps of Yellowstone's thermal areas. We include an appendix containing the names and characteristics of Yellowstone's thermal areas, georeferenced TIFF files containing ASTER thermal imagery, and several spatial data sets in Esri shapefile format.

\section{Introduction}

The Yellowstone geothermal system is the surface manifestation of a partly molten magma reservoir that exists beneath the 0.64 Ma Yellowstone Caldera (Christiansen, 2001). Heat from the magma warms the overlying rock and groundwater reservoirs through conduction and advection. Scientific drilling done in the 1960s indicated that temperatures

\footnotetext{
${ }^{1}$ U.S. Geological Survey.
}

${ }^{2}$ Yellowstone Center for Resources. increase with depth along the boiling curve of water and along a near-hydrostatic pressure gradient beneath most of the thermal areas (White and others, 1975). Water temperatures in these drill holes have been measured as high as $240^{\circ} \mathrm{C}$ (White and others, 1975), but are inferred to rise above $300^{\circ} \mathrm{C}$ within the deep hydrothermal reservoirs (Fournier, 1989). At the surface, there are more than 10,000 individual thermal features in Yellowstone National Park, including hot springs, geysers, fumaroles, and mud pots. These features range in size from a few centimeters to tens of meters across; they range in temperature from tens of degrees Celsius up to, and occasionally above, boiling (92-94 ${ }^{\circ} \mathrm{C}$ at typical elevations in Yellowstone); and they are clustered together into more than 100 distinct thermal areas, mostly concentrated along pre-existing structures such as the ring-fracture system of the $0.64 \mathrm{Ma}$ Yellowstone Caldera, along edges of resurgent domes, or along edges of intra-caldera rhyolite flows (Christiansen, 2001) (fig. 1). Yellowstone's thermal areas cover a total of $\sim 65 \mathrm{~km}^{2}$. Although the combined total area constitutes only about 0.7 percent of Yellowstone National Park, the typical geothermal heat flux (GHF) from these thermal areas (in watts per square meter or $\mathrm{W} / \mathrm{m}^{2}$ ) is estimated to be 300-500 times that of the average continental crust (Pollack and others, 1993; Vaughan and others, 2012).

Mapping thermal areas at Yellowstone is an important step in (1) monitoring baseline thermal activity to better detect and understand anomalous future hydrothermal and (or) volcanic activity; and (2) monitoring changes in thermal areas to support decisions regarding Yellowstone National Park's infrastructure, resources, and visitor safety. The sheer number of individual thermal features, their relative inaccessibility, and their broad distribution make it infeasible to regularly record surface temperatures at all of the known thermal features using field-based instruments. Additional challenges of monitoring GHF from Yellowstone's thermal areas are the temporal variability in surface temperatures (including diurnal, seasonal, and decadal variations), and the subtlety of the magnitude of thermal features in both spatial size and absolute temperature. Heasler and others (2009) discuss a variety of techniques and instruments used to measure temperatures at thermal areas. At Yellowstone, the surficial expression of thermal areas are monitored with in-place temperature data loggers; ground-, helicopter-, and airplane-based thermal infrared camera 


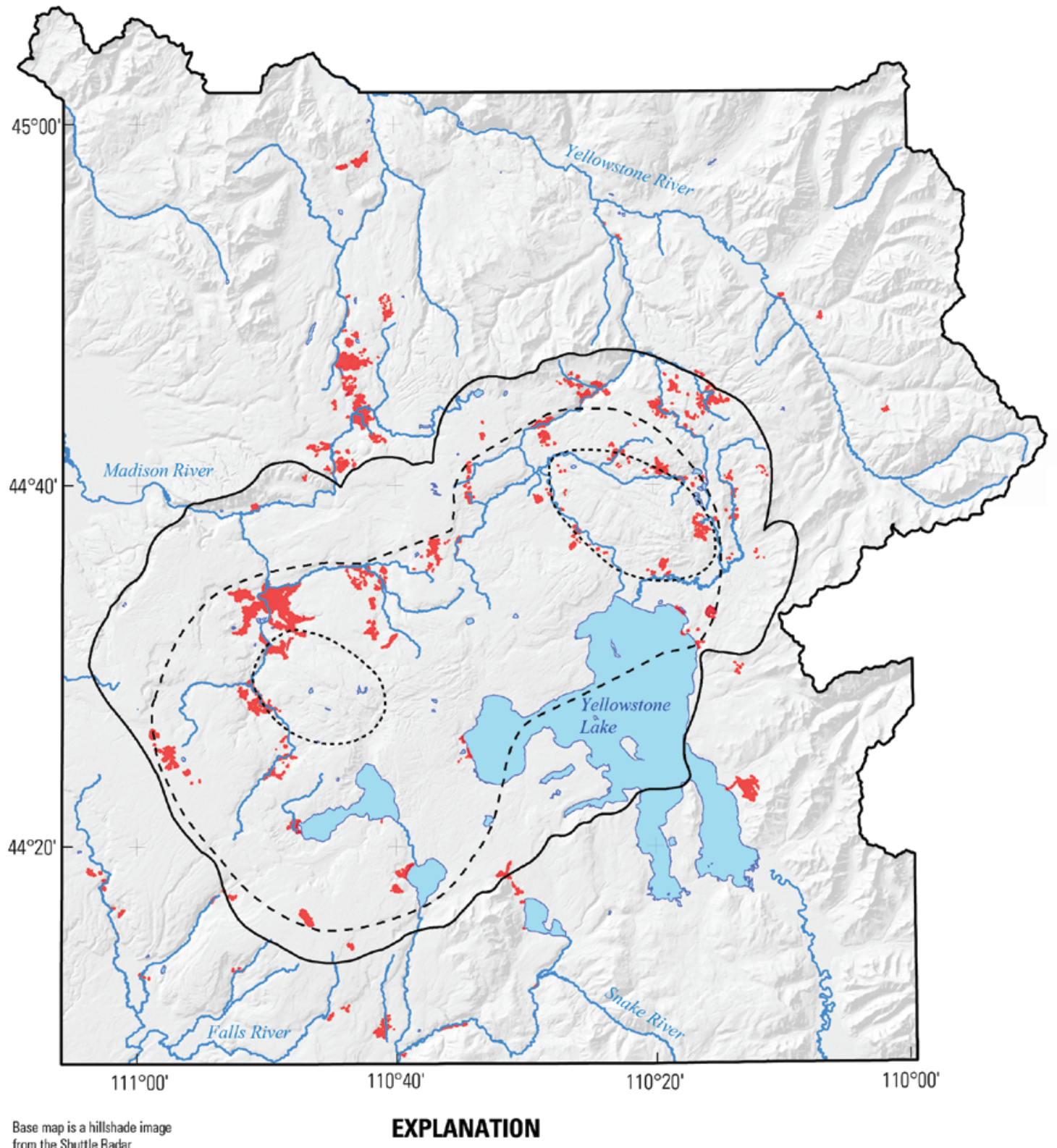

Base map is a hillshade im

Topography Mission

Topography Mission
digital elevation model.

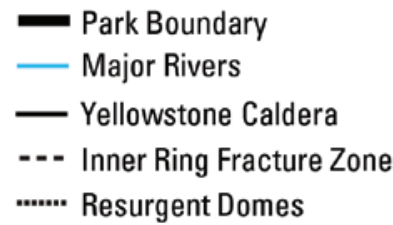

Thermal Areas

Large Lakes

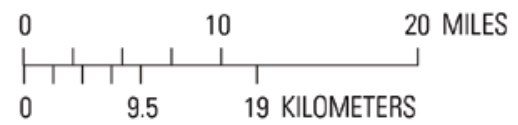

Figure 1. Map of Yellowstone National Park showing location of thermal areas in red (modified from Vaughan and others, 2012). Thermal area polygons are located and digitized based on field mapping (R. Hutchinson, Yellowstone National Park, unpub. data, 1997), digitization from 1-m visible-color orthophotos from the National Agriculture Imagery Program, and Advanced Spaceborne Thermal Emission and Reflection Radiometer hot-pixel mapping from this study. The Yellowstone Caldera boundary, ring fracture zone, and resurgent domes are adapted from Christensen (2001). All other features are available from the National Park Service (2011). The background is a hillshade image from the Shuttle Radar Topography Mission digital elevation model. 
surveillance, (Heasler and others, 2009; Jaworowski and others, 2010, Neale and others, 2011); the Landsat Enhanced Thematic Mapper Plus sensor (Watson and others, 2008; Savage and others, 2012); and the Advanced Spaceborne Thermal Emission and Reflection Radiometer (ASTER; Vaughan and others, 2012).

Most estimates of GHF and total heat output from Yellowstone are based on the emission of dissolved chloride $(\mathrm{Cl})$ exiting the Yellowstone hydrothermal system by way of rivers. Ellis and Wilson (1955) first proposed relating the discharge of $\mathrm{Cl}^{-}$from hydrothermal systems to an enthalpy flux. This $\mathrm{Cl}^{-}$inventory method assumes that the $\mathrm{Cl}^{-}$in waters that drain a hydrothermal region is predominantly derived from a deep homogeneous fluid reservoir with a known temperature. At Yellowstone, estimates of total heat output (power output) range from 4.5 to 6.6 gigawatts (GW) using this technique (Fournier and others, 1976; Fournier, 1979; Ingebritsen and others, 2001; Friedman and Norton, 2007; Hurwitz and others, 2007; Lowenstern and Hurwitz, 2008; Hurwitz and others, 2012).

Because of uncertainties in the assumed parameters of the $\mathrm{Cl}^{-}$inventory method, and because the timing of the release of Cl-rich fluids is tied strongly to hydrologic processes such as precipitation and seasonal flow variations, the total heat output estimated by this method could range from 4 to 8 GW (Hurwitz and others, 2007; Hurwitz and others, 2012). The $\mathrm{Cl}^{-}$inventory method ideally provides an estimate of the total convective GHF through the crust, but it may neglect conduction of heat through rock that is unaffected by movement of water and steam. Using in-place gas and temperature measurements, Hurwitz and others (2012) estimated the combined conductive and advective heat output and GHF at two vapor-dominated acid-sulfate thermal areas, and they extrapolated these values to the other $\sim 35 \mathrm{~km}^{2}$ of vapor-dominated areas.

In contrast, thermal infrared (TIR) remote sensing measurements are capable of concurrently imaging almost all of Yellowstone's thermal areas, though they only detect the radiative component of heat leaving the surface, irrespective of how it arrived there. There are other processes that remove heat from the surface- in particular phase changes (evaporation and boiling of water, melting of snow and ice) and convective heat transfer to the atmosphere- that are not clearly discernible with TIR remote sensing measurements. In most locations the overwhelming majority of the surface heating is from the Sun. This is why nighttime TIR remote sensing data are best suited to evaluate radiative GHF. It is important to recognize the relative modes of heat transfer in the crust and their bearing on heat discharge from multiphase geothermal systems, and that there is no single technique capable of estimating the total amount of heat flux or heat output.

The purpose of this work is to update and refine the existing database of mapped thermal areas in Yellowstone using ASTER TIR remote sensing data, generate temperature and GHF anomaly maps for the Yellowstone geothermal area, and make maps of Yellowstone's thermal areas available in downloadable file formats.

\section{Terminology}

There are some ambiguities in the literature regarding the terminology used to describe heat flux, sometimes referred to as heat flow. In the field of thermodynamics, heat (measured in Joules) is energy that is transferred from one material to another, either by radiation, conduction, advection, or convection. Advection is heat transfer by the bulk flow of fluid mass, such as hot fluids moving through fractures in the crust. This is distinguished from convection, which is a combination of conduction within the fluid and advection (bulk fluid movement). Heat flux is defined as the rate of heat transfer through a given surface, and is measured in Joules per second per unit area (or watts per unit area). Geothermal heat flux (GHF) is the component of the heat flux that is geothermal in origin, that is, produced by Earth's internal heat (also measured in watts per unit area). In the field of radiometry, the power of electromagnetic energy per unit area (in watts per unit area) incident upon a surface is called irradiance-and is called radiant emittance if the energy is radiated away from a surface. The term radiant flux is a measure of the total power of electromagnetic radiation emitted from a surface (of a certain area), and is measured in watts (Boyd, 1983). Confusion arises when trying to compare the geothermal component of heat flux (in watts per unit area) to the geothermal component of the radiant flux (in watts). In the literature the terms heat flow, heat flux, and geothermal heat flux are sometimes used synonymously and the units for these terms are reported in either watts, or watts per unit area, with both units sometimes being used for the same term (Fournier and others, 1976; Fournier, 1989; Lowenstern and others, 2006; Hurwitz and others, 2007; Vaughan and others, 2012; Savage and others, 2012; Hurwitz and others, 2012).

To clarify, we report the units of heat flux or geothermal heat flux in watts per unit area, and the units of heat output in watts (Werner and others, 2008; Hurwitz and others, 2012). Remote sensing measurements of electromagnetic radiation emitted from a surface as a result of geothermal heating are reported in radiometry units: geothermal radiant emittance (in watts per unit area) is the power per unit area of electromagnetic radiation emitted from the surface as a result of geothermal (and not solar) heating, and it is therefore comparable to geothermal heat flux. By multiplying geothermal radiant emittance by the area measured, geothermal radiant flux, reported in watts, is the radiative component of the surface radiant flux that is geothermal (and not solar) in origin, and it is therefore comparable to heat output.

We also adopt the following definitions from Jaworowski and others (2010): A thermal area is a contiguous geologic unit generally including one or more thermal features, bounded by the maximum aerial extent of hydrothermally altered ground, hydrothermal mineral deposits, geothermal gas emissions, or heated ground. A thermal group is a subdivision of a thermal area that contains one or more thermal features and can be isolated from other groups based on physiographic, hydrologic, or geochemical parameters. A thermal feature is a vent, or small 
cluster of related vents, emitting gases or hot water, or both. A thermal drainage is a physiographic or hydrologic drainage to which heated waters are contributed by adjacent thermal areas. For example, Wall Pool and Black Opal Pool are thermal features in the Biscuit Basin thermal group, which is part of the Upper Geyser Basin thermal area; these features contribute thermal waters to the Firehole River thermal drainage (Vaughan and others, 2012).

Neutral chloride thermal areas are dominated by neutralto-alkaline, $\mathrm{Cl}$-rich, silica-saturated, thermal waters that reach the surface as continuously discharging hot springs or geysers. These features tend to be located in lower elevation thermal basins within Yellowstone (including Upper, Midway, and Lower Geyser Basins) where they precipitate amorphous silica (sinter) around the edges of pools and along outflow drainages of geysers (Fournier, 1989; Christiansen and others, 2007; Lowenstern and Hurwitz, 2008). These Cl-rich waters less commonly reach the surface at higher elevations (for example, Roaring Mountain, Sulfur Hills, and the Mud Volcano area), likely because they undergo boiling in the subsurface to produce $\mathrm{H}_{2} \mathrm{O}$ steam, $\mathrm{CO}_{2}, \mathrm{H}_{2} \mathrm{~S}$, and other gases that rise to the surface. These steam-heated acid-sulfate thermal areas are characterized by oxidation of $\mathrm{H}_{2} \mathrm{~S}$, aided by microbial activity, which creates sulfuric acid that alters the subsurface rocks into clay minerals (forming mud pots) or acid-sulfate minerals with abundant fumaroles (Fournier, 1989; Lowenstern and Hurwitz, 2008; Nordstrom and others, 2009).

\section{Data}

The ASTER instrument was launched on NASA's Terra spacecraft in December 1999. ASTER provides radiance measurements in three visible and near infrared (0.5-0.8 microns) channels at $15 \mathrm{~m}$ per pixel, six short-wave infrared (1.6-2.4 microns) channels at $30 \mathrm{~m}$ per pixel, and five TIR (8-12 microns) channels at $90 \mathrm{~m}$ per pixel (Yamaguchi and others, 1998). The ASTER instrument is not constantly acquiring data. Rather, ASTER data are acquired in response to individual data acquisition requests, or in emergency response to natural disasters (Ramsey and others, 2004). Each ASTER image covers an area of $60 \mathrm{~km}$ by $60 \mathrm{~km}$ (or $3600 \mathrm{~km}^{2}$ ), thus multiple scenes were required to cover all of Yellowstone National Park $\left(\sim 8,900 \mathrm{~km}^{2}\right)$. Since its launch, ASTER data have been acquired over Yellowstone on 152 dates (totaling more than 300 individual scenes, as on most dates $2-3$ scenes were acquired along the orbit track). Of these 152 acquisition dates, 41 percent were cloud free, 20 percent were partly cloudy, and the rest were too cloudy to be useful. About 14 percent of these scenes were acquired at night, between 10:30 and 11:30 p.m. local time. Nighttime data are ideal for isolating the surface-emitted radiance component from subtle thermal areas because thermal contrast is increased at night. Nighttime data acquired from January through May are the most useful; during this time lakes with little to no geothermal input are frozen, which helps differentiate ambient areas from those with geothermal input. To measure radiance and surface temperature from all the thermal areas in Yellowstone, with at least one ASTER TIR image that met the ideal criteria (clear, nighttime, in winter), four acquisition dates were used (November 4, 2002; January 28, 2010; February 11, 2010; and February 20, 2010). The November 4, 2002 image is not an ideal winter time image, but was used to supplement coverage of some thermal areas in the southwest section of Yellowstone that were not covered by other nighttime scenes.

The ASTER data products used in this work include ASTER level 1B (ASTL1B) radiometrically calibrated, geometrically corrected at-sensor radiance; AST09T atmospherically corrected at-surface TIR radiance (Thome and others, 1998); AST05 surface emissivity; and AST08 surface kinetic temperature data (Gillespie and others, 1998). The AST09T at-surface radiance data contain TIR spectral radiance values for down-welling reflected sky radiance, which can be subtracted from the total "land leaving" radiance component to isolate the emitted surface radiance component (Palluconi and others, 1999). The AST05 and AST08 data products are produced by the temperature-emissivity separation algorithm (Gillespie and others, 1998). Because different overlapping ASTER scenes were used to calculate surface temperature and radiant GHF, to be consistent, ASTER emissivity data for Yellowstone were derived from the North American ASTER Land Surface Emissivity Database (Hulley and Hook, 2009).

Maps of Yellowstone's thermal areas were initially obtained from a geographic information system (GIS) geodatabase provided by the Spatial Analysis Center at the Yellowstone Center for Resources in Yellowstone National Park. The thermal area polygon geodatabase (TAPG) was initially based on field mapping (by R. Hutchinson, unpub. data, 1997) that was digitized over 1-m-pixel visible-color orthophotos from the National Agriculture Imagery Program (NAIP), acquired in 2006 (fig. 2). The thermal inventory geodatabase (TIG), is a point database derived from field-based GPS locations of individual thermal features in Yellowstone (fig. 3). For more information about the TIG data see the Montana State University Research Coordination Network for an interactive series of maps (2007).

\section{Data Processing and Interpretation}

\section{ASTER Thermal Pixel Mapping}

Most thermal areas that were clearly identified as bright (warm) pixels in the ASTER TIR images were spatially coincident with thermal areas in the TAPG. Occasionally, the geometric (latitude/longitude) information contained in the ASTL1B nighttime data was observed to be inaccurate. The TAPG and corresponding NAIP orthophotos were used to correct the geospatial information in these ASTER scenes. By comparing the location and spatial distribution of anomalously bright 


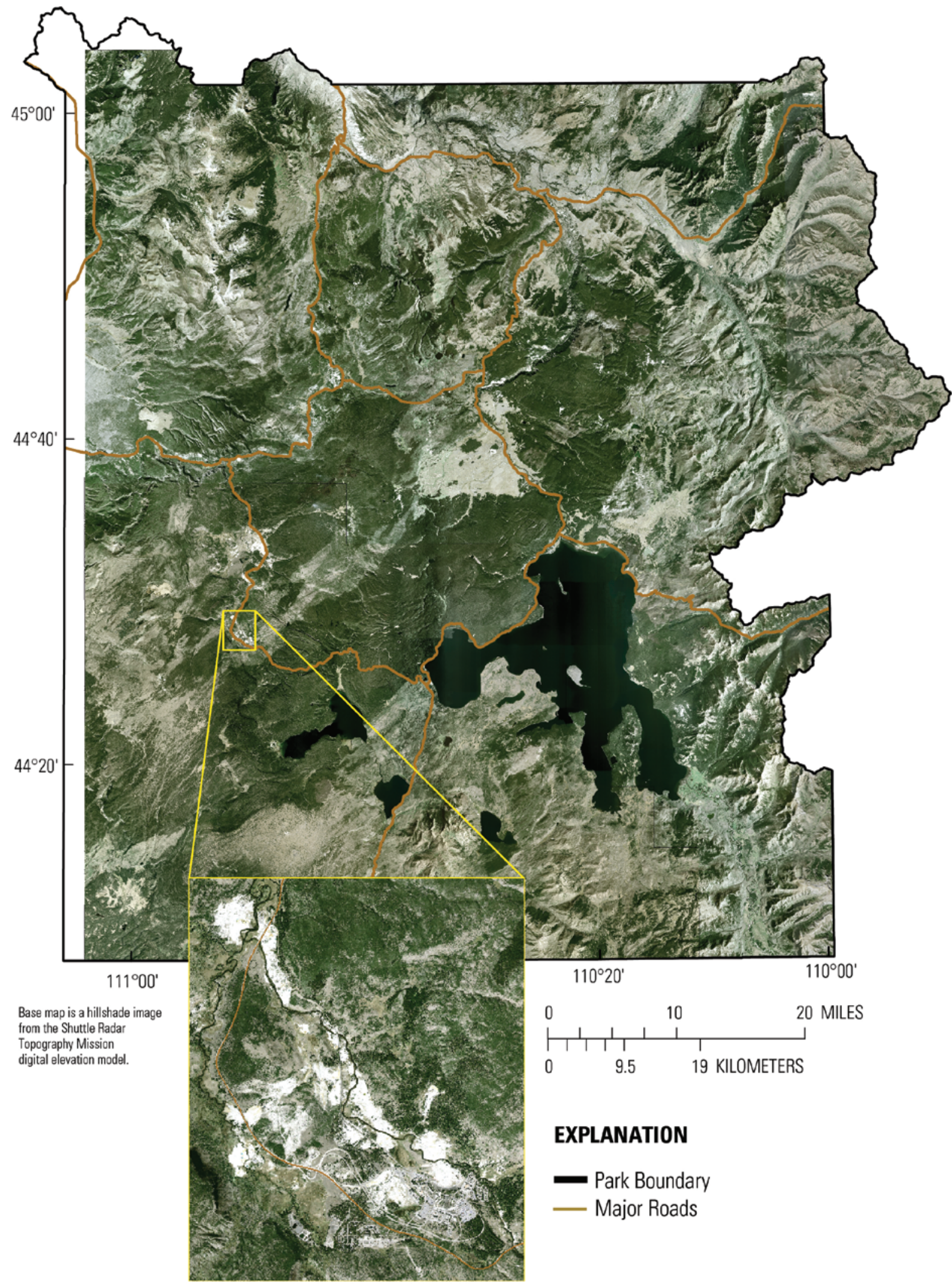

Figure 2. Map of Yellowstone National Park overlaying aerial orthophotography from the National Agriculture Imagery Program (2006). Inset shows more spatial detail within the Upper Geyser Basin. 


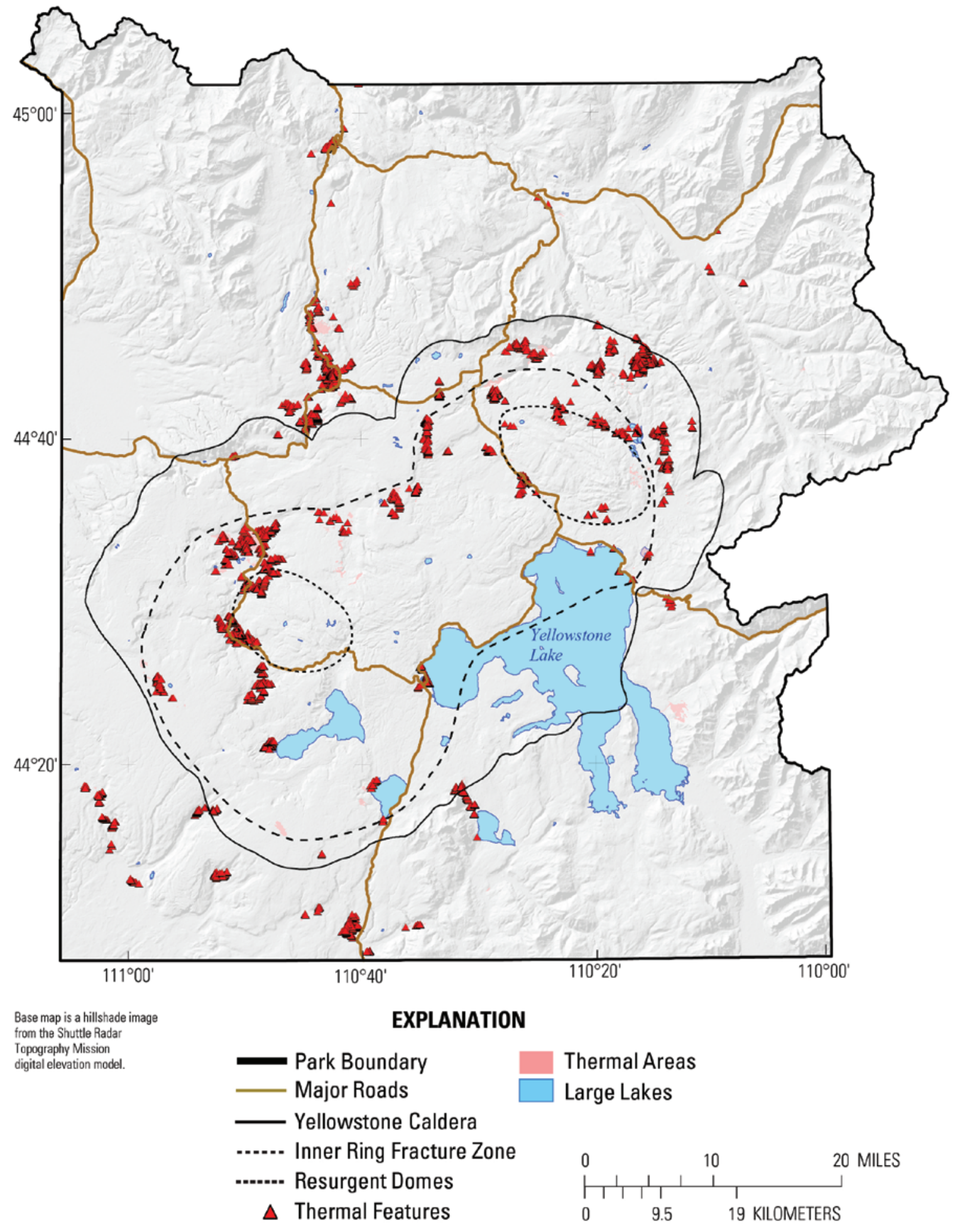

Figure 3. Map of Yellowstone National Park showing location of over 10,000 individual thermal features (red triangles), from the Montana State University Research Coordination Network thermal inventory (2007). The background is a hillshade image from the Shuttle Radar Topography Mission digital elevation model. 
(warm) pixels in the ASTER TIR data to the accurate locations of known warm targets (from the TAPG), ASTL1B data were observed to be 0 to 1 pixels off in latitude, and 0 to 9 pixels off in longitude. A manual correction of the ASTER data geocoding by translating the image pixels to match corresponding (accurately located) thermal areas was found to be sufficient to attain a geometric accuracy of \pm 1 pixel, without any pixel resampling, and was applied as needed to ASTER TIR data products (fig. 4).

In the NAIP imagery, thermal areas appear largely free of vegetation, exposing relatively bright, white areas that reflect the presence of acid-sulfate and clay alteration minerals, siliceous sinter, or travertine deposits (fig. 2). Large lakes appear dark. Open fields of grass are tan to light green and grade into darker green with increasing thickness of forested area. Because there is no surface temperature information contained in the NAIP imagery, some thermal areas that are not thermally emissive but still barren of vegetation may be visually similar to thermally emissive thermal areas. An example is Brimstone Basin, a large, vegetation-free, acid-sulfate altered area located near the southeast arm of Yellowstone Lake (fig. 5A, B). Although Brimstone Basin lacks the elevated surface temperatures associated with active acid-sulfate processes, such as warm mud pots or fumaroles, it is actively degassing significant amounts of $\mathrm{CO}_{2}$ and $\mathrm{H}_{2} \mathrm{~S}$ (Bergfeld and others, 2012). ASTER nighttime data indicate that the TIR emitted radiance from this area is less than or equal to that from its surroundings. Owing to the exposed areas lacking significant geothermal heat, lacking vegetation (which retains heat), and having more exposed snow cover than the surrounding forest, this thermal area generally appears colder than its surroundings. Field investigations have also noted a lack of thermal features in the Brimstone Basin area (Bergfeld and others, 2012).

Some areas mapped as thermal areas in the TAPG appear to have a surface expression of past hydrothermal activity, but they show no evidence of current thermal emission or active degassing. The Central Pitchstone Plateau thermal area (fig. $5 C, D)$ is an example. Although the composition of the bright white areas in the NAIP imagery and any active degassing has yet to be investigated in the field, the ASTER TIR data show no evidence of radiant heat flux at the surface here. Most thermal areas mapped in the TAPG, with numerous thermal features (points) mapped in the TIG, also exhibited a measureable surface thermal anomaly in the ASTER TIR data (fig. 5E, F).

Because these areas all fall under the working definition of "thermal area," they are mapped as such. On the basis of surface-temperature information from ASTER TIR data, surfacecover information from the NAIP imagery, and field-based mapping of thermal area boundaries and individual thermal features, we propose that thermal areas in Yellowstone can be divided into three groups for the purpose of satellite classification of thermal areas: (1) thermally emissive thermal areas, (2) cold degassing thermal areas, and (3) non-active thermal areas (with no currently known or detectable thermal or gas emissions).

The ASTER TIR data also helped identify warm areas that were not recorded in either the TIG or the TAPG. For example, just south of the Shoshone Geyser Basin, there is a large wetland area where water enters the west side of Shoshone Lake from the Shoshone Creek thermal drainage. In the winter, nighttime imagery a temperature difference is apparent between the wetland area and Shoshone Lake, which is frozen (fig. 6A, $B)$. The thermal input to Shoshone Creek from the Shoshone Geyser Basin appears to be sufficient to keep the water in this
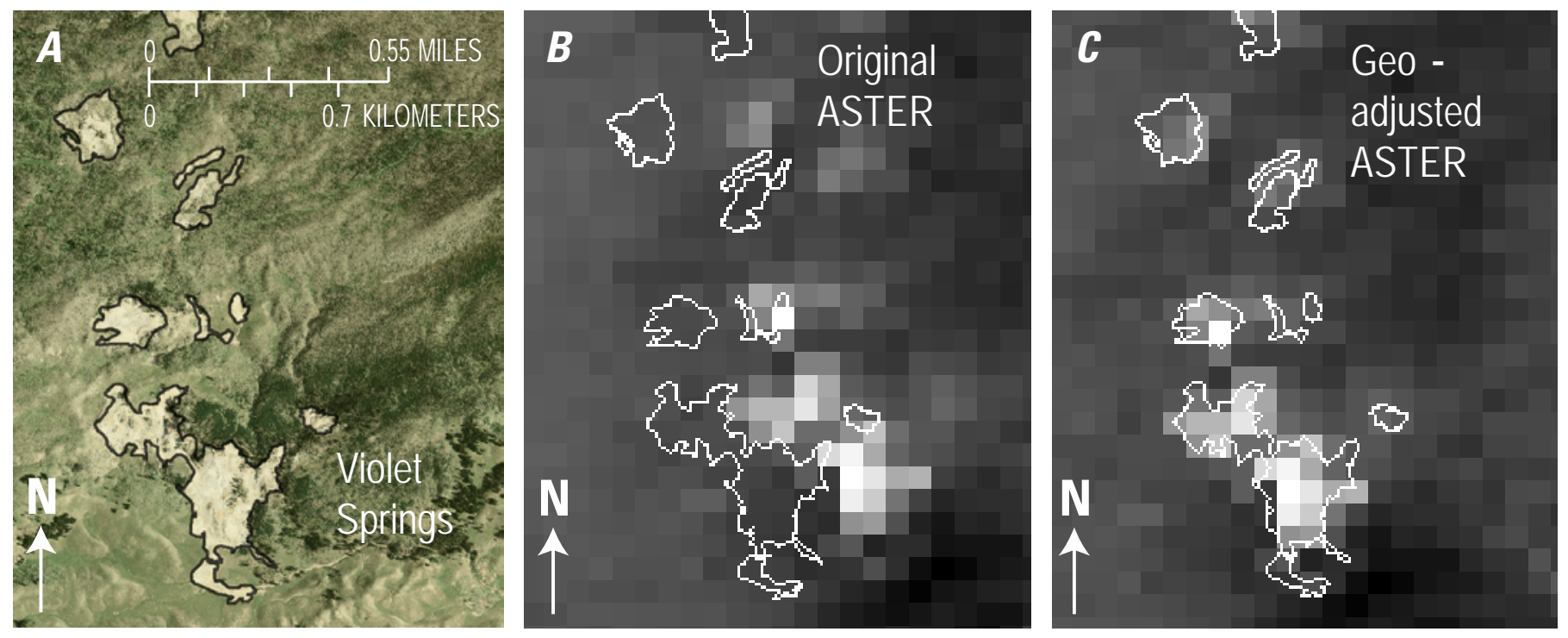

Figure 4. Imagery showing geometric adjustment of thermal infrared data. A, 1-m visible-color image (from the National Agriculture Imagery Program) of the Violet Springs region with thermal areas outlined in black. $B$, Original thermal infrared image from the Advanced Spaceborne Thermal Emission and Reflection Radiometer (ASTER) L1B nighttime dataset [channel 31 (11 micron)], acquired on November 11, 2010. Note the corresponding bright pixels (warm) are offset 4 pixels to the east relative to the actual locations of thermal areas outlined in white. $C$, Geometrically adjusted ASTER thermal infrared image (translated 4 pixels to the West). Each image is centered on $44.660^{\circ}$ N., $110.568^{\circ}$ W. (From Vaughan and others, 2012). 

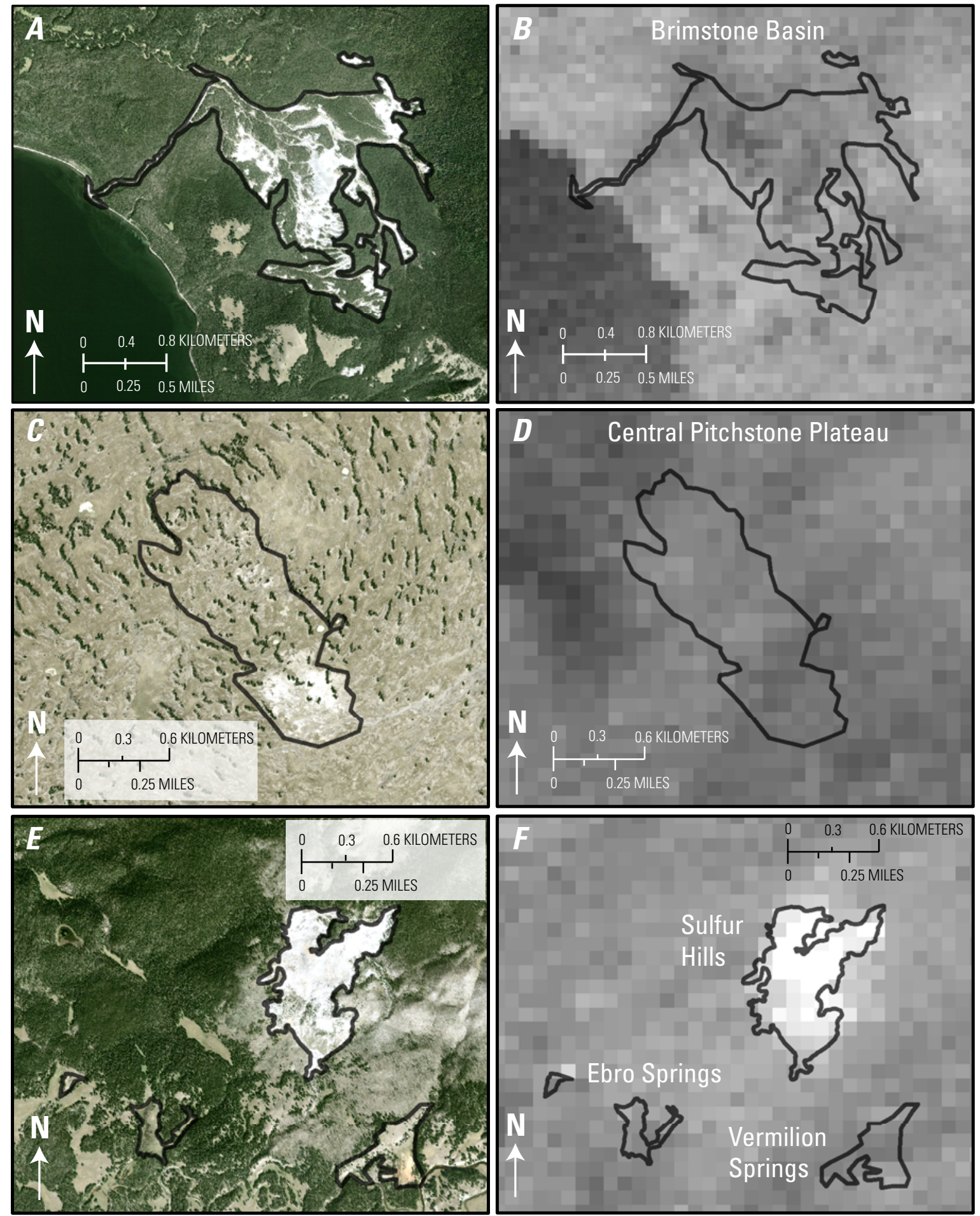

Figure 5. Imagery comparing various types of thermal areas (outlined with black). $A$ and $B, B$ rimstone Basin, a thermal area that is actively degassing, but not thermally emissive. It has sinter deposits and is barren of vegetation. Image is centered on $44.385^{\circ} \mathrm{N}$., $110.22^{\circ} \mathrm{W}$. $C$ and $D$, Central Pitchstone Plateau, a location mapped as a thermal area, but with no evidence of thermal emission or active degassing. It may have some alteration minerals or sinter deposits and is barren of vegetation. Image is centered on $44.267^{\circ} \mathrm{N}$., $110.782^{\circ} \mathrm{W}$. $E$ and $F$, Sulfur Hills, a thermal area with high surface temperatures and boiling fumaroles that are actively degassing. To the west of Sulfur Hills is Ebro Springs, a small $60^{\circ} \mathrm{C}$ spring emanating from a small outcrop. Image is centered on $44.590^{\circ} \mathrm{N} ., 110.326^{\circ} \mathrm{W}$. The backgrounds are visible-color orthophotography from the National Agriculture Imagery Program (left), and thermal infrared imagery from the Advanced Spaceborne Thermal Emission and Reflection Radiometer (right; bright pixels are warmer). 

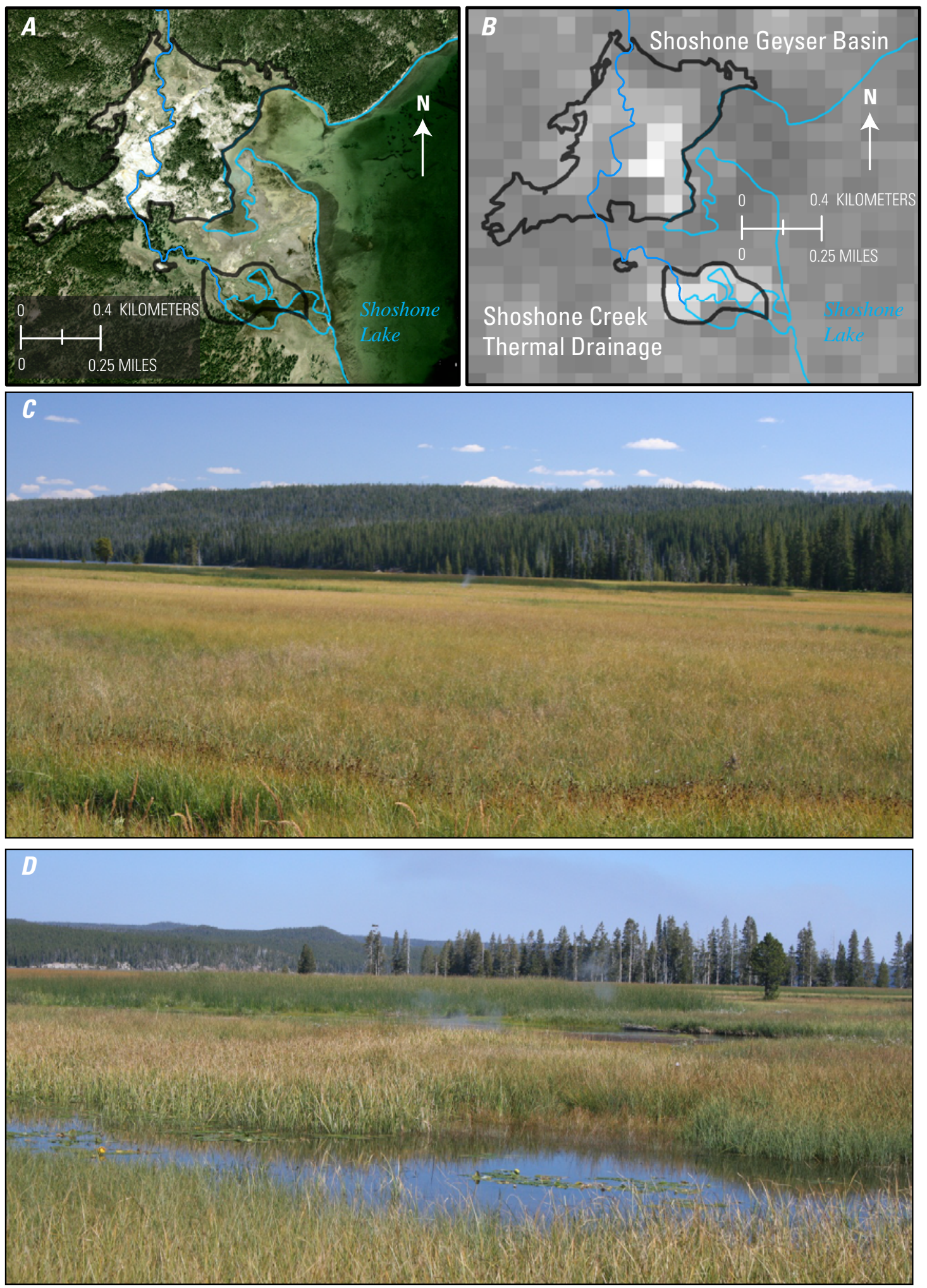

Figure 6. Maps and photographs of Shoshone Geyser Basin and Shoshone Creek thermal drainage. $A$ and $B, 0$ maps Shoshone Lake is outlined in blue; Shoshone Geyser Basin is outlined in black; Shoshone Creek is marked in blue. The images are centered on $44.352^{\circ} \mathrm{N} ., 110.794^{\circ} \mathrm{W}$. The backgrounds are $A$, visible-color orthophotography from the National Agriculture Imagery Program, and $B$, winter nighttime thermal infrared imagery from the Advanced Spaceborne Thermal Emission and Reflection Radiometer (bright pixels are warmer). $C$ and $D$, Photos of the Shoshone Creek thermal drainage showing the inaccessible marshy area where Shoshone Creek enters Shoshone Lake, with some steam in the distance (acquired in September 2011). Photographs by R. Greg Vaughan, U.S. Geological Survey. 
marshy area distinctly warmer than the lake in the winter (with possibly some unfrozen, flowing water in the marsh), and warm enough to produce visible steam on a summer day. A field investigation during the summer of 2011 revealed steaming surface water in this area, inaccessible by foot as the marsh was too deep (fig. 6C, D). This thermal drainage is an example of an area that is not part of the mapped thermal areas and does not contain any distinct thermal features, but that radiates significant geothermal heat.

Finally, there are likely to be areas that are not thermally emissive at the detection limit of ASTER TIR data (90-m pixels), but these areas have features that emit thermal radiance that is too subtle to be detected. Areas that have been mapped in the TAPG and contain TIG points, but that do not appear as warm pixel anomalies in the ASTER TIR data could be investigated in the field in the future.

\section{ASTER TIR Background Subtraction}

The use of nighttime ASTER TIR data minimizes, but does not completely eliminate, the influence of the Sun. This is partly because the nighttime data are always acquired $\sim 11$ p.m. local time for the Yellowstone area and there is a major component of surface emitted radiance that is not geothermal in origin, but related to solar heating earlier in the day that slowly dissipates overnight. Such heating is a function of topography (elevation, slope, and aspect), land-surface cover, lithology, and previous weather conditions. It is challenging to isolate the geothermal component of radiative heat output from the radiative heat output due to daily solar heating because the geothermal component is less than 1 percent of the total from the entire Yellowstone area (Vaughan and others, 2009; Vaughan and others, 2012).

To isolate this subtle geothermal component of the emitted radiance, a background component was subtracted. Radiant emittance (in watts per square meter) from a proximal, non-geothermal background area with similar topographic and land surface cover characteristics, and of equal area, was subtracted from the total radiant emittance values to derive the geothermal component of radiant emittance. This assumes that the thermal radiance emitted from the background area due to solar heating is very similar to that of the proximal geothermal area. Background areas were chosen based on several criteria: (1) proximity to thermal area, (2) similar elevation and topographic characteristics as the thermal area (to minimize the effects of differential elevation, slope, and aspect), (3) similar surface cover types as the thermal area (to minimize the effects of variable surface emissivities and transpiration in vegetation), and (4) same size (in pixels) as the thermal area. Additionally, areas that had been affected by fires in the last decade were avoided wherever possible because the significant change in surface-cover characteristics caused by a fire could easily be misinterpreted as geothermal change. The presence of small unequally distributed clouds or steam from thermal features remains a source of uncertainty. To first order, a simple subtraction of the background radiance from the thermal area radiance removes the effects of seasonal insolation variations and other effects, leaving radiance values that reflect the geothermal component of the emitted radiance. The background subtraction technique has the advantage of being simple and easy to automate, but the disadvantage of a subjective choice of background area.

\section{Geothermal Radiant Flux}

Geothermal radiant flux was derived for each thermal area in Yellowstone. For pixels covering the parts of each mapped thermal area that were more than $0,1,2,3$, and 4 standard deviations above the mean temperature value of the corresponding background area, pixel temperature values were extracted from the AST08 data. An example from Heart Lake Geyser Basin is shown in figure 7.

Not all parts of mapped thermal areas had significant thermal emission at the time of the ASTER observation. In fact, some ASTER pixels in thermal areas were colder than the mean corresponding background temperature. Therefore, the thermally emissive part of a thermal area was defined as that part with pixel temperatures greater than the mean temperature of the corresponding non-thermal background area. We examined temperature threshold values for the thermal areas, corresponding to $0,1,2,3$, and 4 standard deviations above the mean background temperature. Because the average temperature of the background area was used as the threshold for defining what parts of the corresponding thermal area were thermally emissive, there is some scene dependence and subjectivity to these estimates. For example, if multiple ASTER scenes from different dates cover a particular thermal area, the amount of local cloud cover or thermal fog (condensation of the emitted steam) obscuring the thermal area may be different from one scene to the next, resulting in different geothermal radiant flux estimates. In the cases where the same thermal area was investigated in multiple ASTER scenes acquired on different dates, the maximum value was considered to be the best estimate since the radiative heat flux is only a lower limit on the total geothermal heat flux. Also, because quantification was done only for winter 2010 (with the exception of a few areas from November 2002), we assume no significant temporal variations in temperature and geothermal radiant flux. Ultimately, if enough ASTER scenes are available to make multiple measurements in a similar way, these sources of uncertainty could be better characterized.

The total radiant emittance $\left(M_{T}\right.$, in watts per square meter) from each thermal area was derived on a pixel-by-pixel basis using the Stefan-Boltzmann law $\left(M_{T}=\sigma \varepsilon \mathrm{T}^{4}\right)$, where $\sigma=$ $5.6704 \times 10^{-8} \mathrm{~W} /\left(\mathrm{m}^{2} \mathrm{~K}^{4}\right)$ and $\mathrm{T}$ is the ASTER pixel temperature (in kelvin). Emissivity ( $(\varepsilon)$ for each area was derived from the North American ASTER Land Surface Emissivity Database, which is a seamless database of high-resolution land-surface emissivity for North America derived from standard ASTER emissivity products developed by Hulley and Hook (2009). The geothermal component of the radiant emittance $\left(M_{G}\right)$ was 

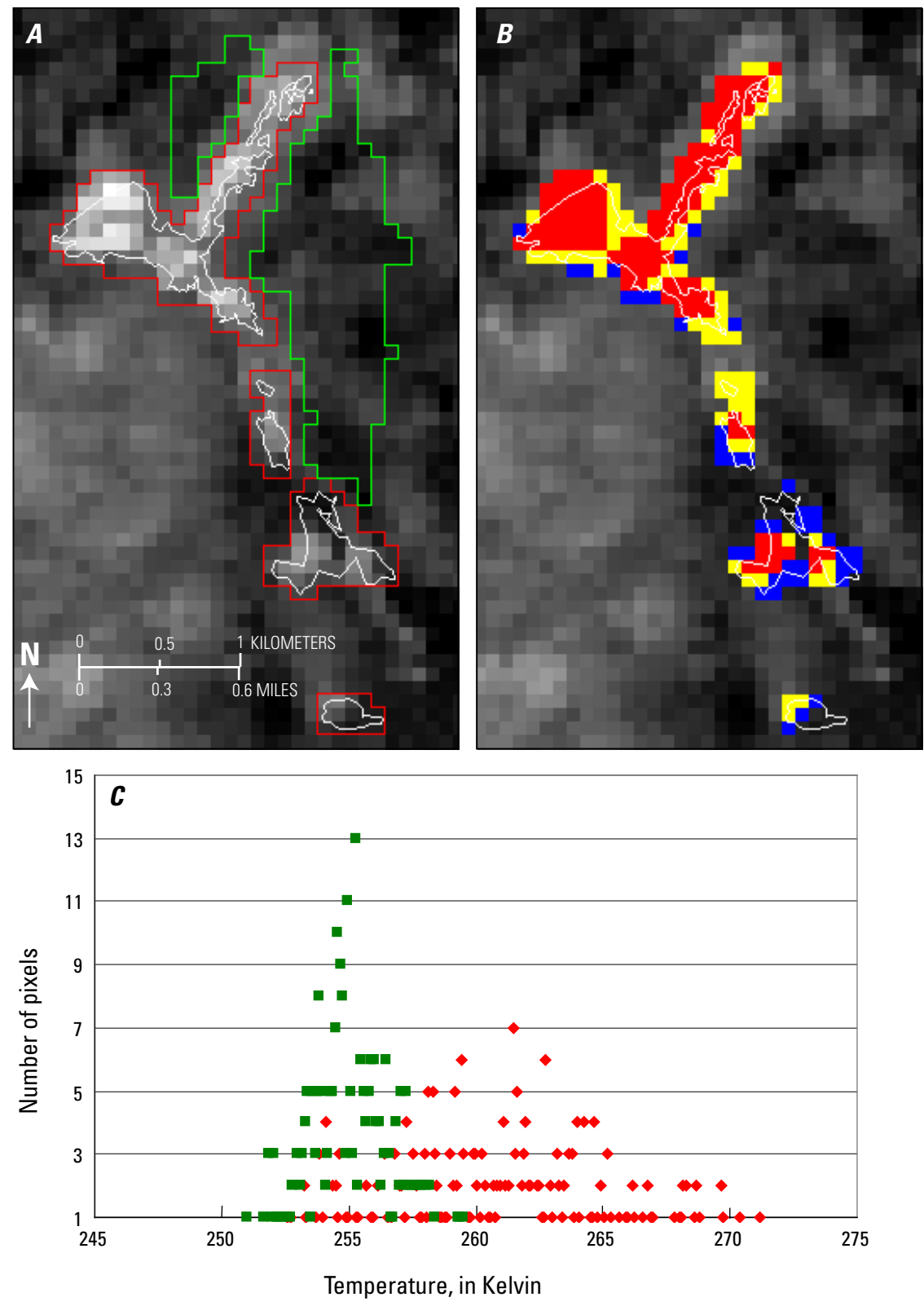

Figure 7. Imagery and histogram of nighttime temperatures at Heart Lake Geyser Basin. A, Thermal infrared imagery with thermal area polygons outlined in white, pixels encompassing the thermal areas outlined in red, and corresponding non-thermal background pixels outlined in green. The image is centered on $44.30^{\circ} \mathrm{N}$., $110.52^{\circ} \mathrm{W}$. $B$, The same image, showing pixels with temperatures greater than the background mean in blue, greater than the background mean +2 standard deviations in yellow, and greater than the background mean +4 standard deviations in red. $C$, Histogram of temperature values (in kelvin) for Heart Lake Geyser Basin (red) and corresponding background area (green). Data were acquired January 28, 2010 by the Advanced Spaceborne Thermal Emission and Reflection Radiometer. Calculated geothermal heat flux values are shown in table 1.

Table 1. Analysis of Heart Lake Geyser Basin thermal infrared data from the Advanced Spaceborne Thermal Emission and Reflection Radiometer.

[SD, Standard Deviation(s)]

\begin{tabular}{lccc}
\hline Warmer than background & Number of pixels & $\begin{array}{c}\text { Geothermal radiant emittance } \\
\left(\mathbf{W} / \mathbf{m}^{2}\right) \text { mean }\end{array}$ & $\begin{array}{c}\text { Geothermal radiant flux (MW) } \\
\text { sum }\end{array}$ \\
\hline Mean & 243 & 25.0 & 49.2 \\
Mean +1 SD & 236 & 28.7 & 49.1 \\
Mean +2 SD & 236 & 28.7 & 49.1 \\
Mean +3 SD & 222 & 31.9 & 48.0 \\
Mean +4 SD & 200 & 35.6 & 45.4 \\
\hline
\end{tabular}


calculated by subtracting the background radiant emittance $\left(M_{B G}\right)$ from the total radiant emittance $\left(M_{T}\right)$. The geothermal radiant flux ( $\phi_{G}$, in gigawatts) was attained by multiplying $M_{G}$ by the corresponding pixel area $\left(8,100 \mathrm{~m}^{2}\right)$, and summed for all the pixels in the thermal area. These calculations were made for every thermal area in Yellowstone - for all the pixels that were greater than $0,1,2,3$, and 4 standard deviations above the background mean.

\section{Updating Thermal Area Maps}

ASTER warm pixel maps were spatially compared to the initial TAPG and the 1-m color NAIP imagery. In an iterative process, the TAPG was used to geocorrect the ASTER data, and the ASTER data were used to enhance the TAPG, guided by the higher spatial resolution NAIP imagery and the TIG. For example, for ASTER warm pixel areas that were outside of the existing TAPG, the NAIP imagery was evaluated for surface cover that resembled thermal areas and the TIG was checked for the presence of point features. If the area was warm (based on ASTER TIR) and looked like a thermal area (minimal vegetation), or contained TIG points, then a new polygon was added to the TAPG. There were some areas mapped in the initial TAPG that were clearly not thermal and did not appear to have been previously. These areas were likely included owing to errors in the polygon digitization and were thus removed in the updated TAPG. There were also areas mapped in the initial TAPG that were previously thermal, but are no longer thermally emissive. These were retained in the TAPG and classified as non-active thermal areas or cold-degassing thermal areas. There were areas that were not included in the initial TAPG, but that did appear to be thermally emissive. These were added to the updated TAPG. Field checking the updates to the TAPG is an ongoing process.

Most thermal areas mapped in the initial TAPG have official names, but some do not. Areas that have a name, but that do not appear to be thermally active were not changed, except to be classified as non-thermally emissive. Of these areas, some are known to be actively degasing, but not currently thermally emissive (such as Brimstone Basin). Some feature classifications were updated for unnamed thermal areas mapped in the original TAPG that are proximal to named thermal areas. Unnamed thermal areas mapped in the original TAPG that are not proximal to named thermal areas were given unofficial names (descriptive placeholders) based on their locations. For example, The Bog Creek thermal area was unofficially named based on its location along Bog Creek. Another example is a small thermal area located on the southeast shore of Shoshone Lake, which was named "Shoshone Lake South” thermal area.

\section{Discussion}

Based on surface temperature measurements made in the field and from high-resolution airborne thermal imagery (Heasler and others, 2009; Jaworowski and others, 2010,
Neale and others, 2011) most acid-sulfate thermal areas are characterized by multiple, small $(<1 \mathrm{~m})$ point sources of high-temperature vents (as high as $\sim 93{ }^{\circ} \mathrm{C}$ ) surrounded by warm ground $\left(30-70{ }^{\circ} \mathrm{C}\right)$. Geyser basins are characterized by multiple meter-scale pools of boiling to sub-boiling water often with warm water draining away, in addition to numerous smaller steam and geyser vents. The maximum ASTER TIR-measured surface temperatures within thermal areas (as high as $24^{\circ} \mathrm{C}$ ) reflect thermal mixing in the spatial dimension with below freezing background surfacesusually from snow as these data were mostly acquired at nighttime in January and February. Thermal imagery indicates that large, warm hot spring pools tend to have the highest temperatures, although the Sulfur Hills acid-sulfate thermal area (fig. 5) is exceptionally hot because of the wide distribution of boiling fumaroles separated by very warm diffusely venting ground, where boiling temperatures are just a few centimeters below the surface. In general, the acidsulfate areas show the highest geothermal radiant emittance (in watts per square meter), although neutral chloride hot spring areas and geyser basins also exhibit high geothermal radiant emittance if they contain large hot spring pools. Examples of theses types of hot spring pools include Grand Prismatic Spring and Excelsior Geyser Crater in Midway Geyser Basin, and Firehole Lake in Lower Geyser Basin (fig. 8A, B). Another large, warm body of water is Turbid Lake, which is a 1-km-diameter hydrothermal explosion crater (Morgan and others, 2009). It is adjacent to the Turbid Springs acid-sulfate thermal area and is notable as one of the largest, at least partly unfrozen, bodies of water in the winter, presumably owing to input of thermal waters from Turbid Springs on the south shore of the lake, and also possibly due to underwater thermal vents (fig. $8 C, D$ ).

The average GHF for continental crust is reported to be $0.065 \mathrm{~W} / \mathrm{m}^{2}$ (Pollack and others, 1993). Yellowstone geothermal system is often cited in the literature as having a GHF of $\sim 2 \mathrm{~W} / \mathrm{m}^{2}$, about 30 times higher than the average heat flux for continental crust (Fournier, 1989; Smith and Braile, 1994; Lowenstern and others, 2006; Lowenstern and Hurwitz, 2008; Farrell and others, 2009; Smith and others, 2009, Savage and others, 2010). This heat flux value is attributed to an area Fournier (1989) described as “... the entire 2,500 $\mathrm{km}^{2}$ of the Yellowstone caldera." However, much of Yellowstone's heat is emitted from areas outside the Caldera (such as Norris Geyser Basin), so it is important to attribute heat flux estimates to specific areas when comparing them to average continental crust. Based on ASTER TIR measurements, for Yellowstone's active thermal areas (a total of $\sim 65 \mathrm{~km}^{2}$ ), the average geothermal radiant emittance, a proxy for heat flux, is $21 \mathrm{~W} / \mathrm{m}^{2}$ (>300 times the continental average), and for the hottest parts of the active thermal areas, is $37 \mathrm{~W} / \mathrm{m}^{2}$ ( $>500$ times the continental average). The total geothermal radiant flux summed for all of the active thermal areas, which is comparable to heat output, is about $2.0 \mathrm{GW}$. This is within a factor of 2 or 3 of the total heat output of 4.5-6.6 GW, estimated using the $\mathrm{Cl}^{-}$inventory method 

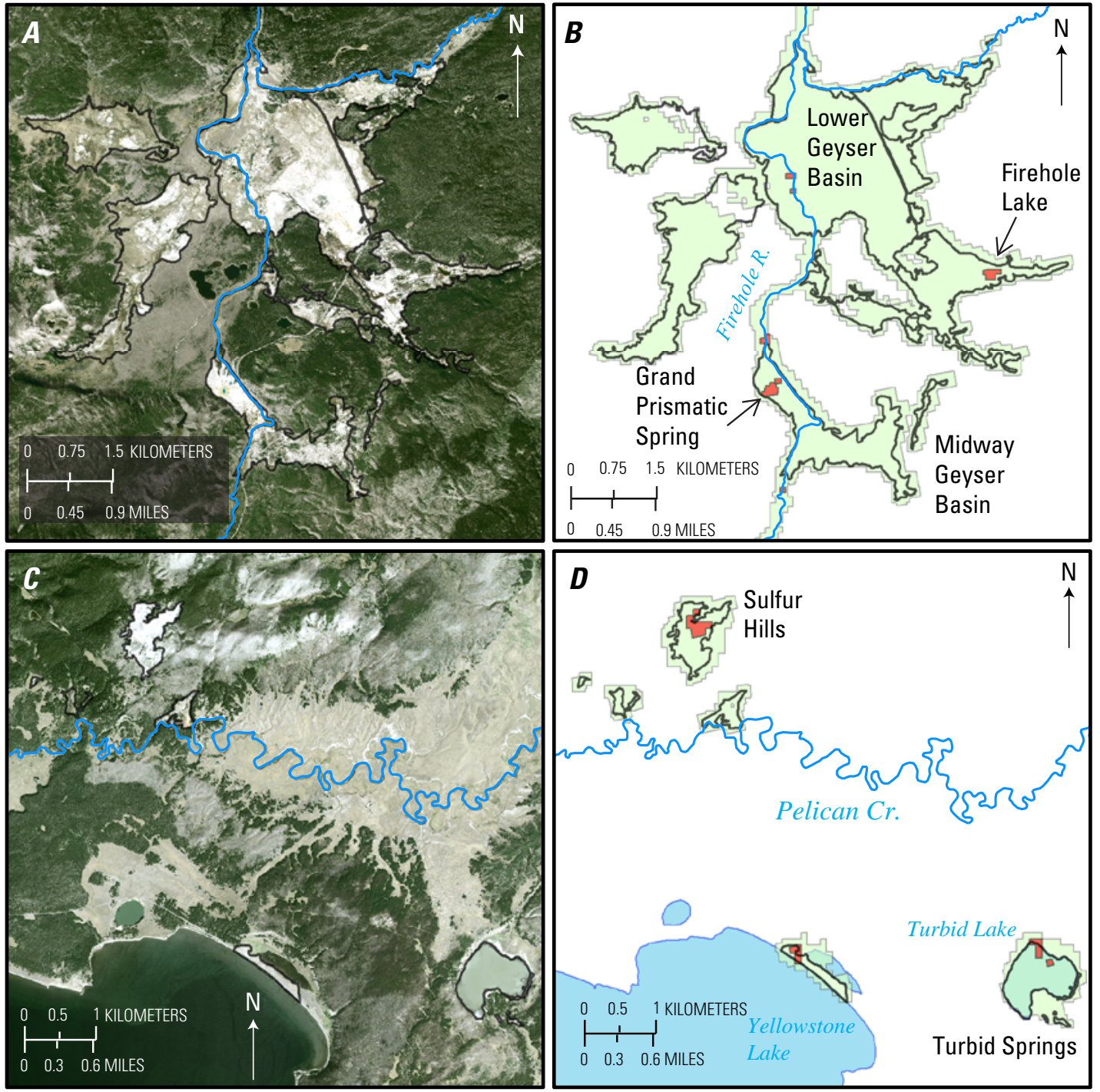

Figure 8. Maps comparing thermal area polygons and thermal pixel polygons. Thermal area polygons (black) overlay visible-color orthophotography from the National Agriculture Imagery Program (left), and Advanced Spaceborne Thermal Emission and Reflection Radiometer-based thermal pixel polygons (right). Thermal pixel polygons with temperatures greater than the mean background are light green and the hottest pixels are red. $A$ and $B$, Lower Geyser Basin and Midway Geyser Basin, including the locations of Grand Prismatic Spring, Firehole River, and Firehole Lake. The maps are centered on $44.542^{\circ}$ N., $110.825^{\circ} \mathrm{W}$. $C$ and $D$, Sulfur Hills, Turbid Springs, and Turbid Lake. The maps are centered on $44.572^{\circ} \mathrm{N} ., 110.296^{\circ} \mathrm{W}$
(Fournier and others, 1976; Fournier, 1979; Ingebritsen and others, 2001; Friedman and Norton, 2007; Hurwitz and others, 2007; Lowenstern and Hurwitz, 2008; Hurwitz and others, 2012).

The total heat output estimated using the $\mathrm{Cl}^{-}$inventory method may not be sensitive to conductive heat loss to surrounding rocks, and the total heat output estimated using TIR remote sensing (radiant flux) is not sensitive to heat loss due to advection of water and steam at the surface (though effort was made to include radiant emission from some thermal drainages). However, determining Yellowstone's total heat output is not as simple as combining these heat output values. Much of the measured radiant heat flux constitutes a part of the heat loss measured using the $\mathrm{Cl}^{-}$inventory method, and it is expected to be an underestimate owing to the effects of spatial resolution, evaporative cooling, and steam interference (Vaughan and others, 2012). Ongoing work in TIR data analysis and field validation will refine the estimates of total heat output.

\section{Summary and Conclusions}

There is currently no single technique that provides a direct measure of the total GHF or heat output from the Yellowstone geothermal system and how it varies on different temporal and spatial scales. Satellite TIR observations provide a synoptic view at a variety of temporal and spatial scales and are well suited to overcoming some of the challenges associated with geothermal monitoring. However, it remains challenging to reliably measure subtle temporal and spatial thermal variations of small, discontinuous thermal features. To address these challenges and build on previous work, the goals of this study were to investigate and develop satellite 
TIR remote sensing techniques to help achieve the thermal monitoring goals. To accomplish this, we used ASTER TIR data to estimate the geothermal radiant emittance and radiant flux of each thermal area individually, and for all of the thermal areas combined. We compared our results to other estimates of Yellowstone's total heat flux and heat output, and created enhanced maps of the active thermal areas, forming new distinctions between thermally emissive, cold degassing, and non-active thermal areas. The NAIP imagery and field-based mapping provided information about the surface composition and visual appearance of an area. The Research Coordination Network TIG points provided field-based information about where many active thermal features were located, and the ASTER TIR data provided information about the location of features that are thermally emissive (above the detection limits of the ASTER TIR data).

Calculations of the total geothermal radiant flux using ASTER TIR data resulted in estimates around $2 \mathrm{GW}$, which constitutes 25-45 percent of the total heat output estimated using the $\mathrm{Cl}^{-}$inventory method. Although TIR remote sensing may only provide a lower limit estimate of the total heat output, this component of the heat output is one that can be monitored over the entire Yellowstone area, nearly simultaneously and regularly. Furthermore, it is sensitive to changes that may be related to volcanic, tectonic, or hydrothermal processes for both geothermal and volcano monitoring applications. Finally, this work establishes a procedural framework for automated detection and monitoring of thermal variations that may be precursors to volcanic or hydrothermal activity. The implications of it are important to continued geothermal monitoring in Yellowstone and also to volcano and geothermal monitoring on a global scale.

\section{Database Contents}

The data released with this report include both raster and vector type datasets. The raster data include (1) ASTER TIR temperature imagery from four different dates with adjusted geometric information, and (2) color-coded thermal anomaly maps derived from these data. The vector data include (1) the Thermal Area Polygon Geodatabase (TAPG) shapefile and (2) an ASTER-based thermal pixel polygon geodatabase shapefile. These data sets are available at http://pubs.usgs.gov/ sir/2014/5137/.

\section{Raster Data}

ASTER TIR temperature images were derived from the AST08 surface kinetic temperature data products (Gillespie and others, 1998). Geometric adjustments were applied as described above and the images saved as 32-bit grayscale GeoTIFF images that retain the temperature information (in Celsius) for each pixel. Because AST08 surface kinetic temperature data are produced and distributed in 12-bit unsigned integer format,
AST08 pixel temperatures are initially reported in units of Kelvin scaled by a factor of 10, and pixels with "no data" have a value of 2,000. Converting the pixel temperature values to units in degrees Celsius using $\mathrm{ENVI}^{\circledR}$ software band math results in "no data" values of $-73.149994{ }^{\circ} \mathrm{C}$. In ArcGIS, displaying this "no data” value as no color will remove the black border around the image. The ASTER images from February 11, 2010 and February 20, 2010 are each mosaics of two ASTER scenes. For these mosaics, the "no data" values are $-273.15^{\circ} \mathrm{C}$ and can be displayed with no color in ArcGIS to remove the black border around the image. In the November 4, 2002 image, lakes are not frozen and are thus more radiant than areas on the land surface at night. Thermal areas adjacent to lakes are not discernible under these conditions, but this scene was needed to cover several thermal areas in the southwest part of Yellowstone.

There are two ASTER TIR-based thermal anomaly maps derived for each of the four ASTER acquisition dates: (1) temperature anomaly maps and (2) geothermal radiant emittance anomaly maps. The temperature anomaly maps display pixel temperatures above background (in Celsius) for each thermally emissive thermal area with a rainbow color scale normalized to a maximum temperature anomaly of $30^{\circ} \mathrm{C}$ (fig. 9A). The geothermal radiant emittance anomaly maps display the pixel radiant emittance above background (in watts per square meter) for each thermally emissive thermal area with a rainbow color scale normalized to a maximum radiant emittance anomaly of $100 \mathrm{~W} / \mathrm{m}^{2}$ (fig. 9B). Some thermal areas are imaged by only one of the ASTER acquisition dates. Other thermal areas are imaged multiple times. Differences in the anomaly values between the ASTER dates reflect variability in the measured radiant emittance due to local cloud cover or variable steam and (or) fog interference. There are also some areas mapped that represent thermal drainages, such as the Firehole River, that are not included in the TAPG.

\section{Vector Data}

The TAPG shapefile was initially based on field mapping (by R. Hutchinson, Yellowstone National Park, unpub. data, 1997) and was later digitized from the 1-m color NAIP imagery and thus reveals more spatial detail than the ASTER TIR pixel-based polygons. Updates to the initial TAPG were based on ASTER warm pixel mapping and the TIG, combined with ongoing field validation. The names and characteristics of the thermal areas are listed in appendix 1.

The ASTER-based thermal pixel polygons were derived from the ASTER TIR imagery with 90-m pixels, and the coarse stair-step appearance of the boundaries at less than about 1:50,000 scale reflect the 90 -m pixels. These polygons map thermally emissive thermal areas; they do not include cold degassing or inactive thermal areas, but they do include thermally emissive areas that are not mapped in the TAPG, for example, some thermal drainages. The ASTER-based thermal pixel polygons were mapped at four different temperature threshold levels (greater than background mean; greater than 2 
standard deviations above the background mean; greater than 4 standard deviations above the background mean; and the hottest 1-2 pixels in each area). As a result, they do not contain objective, quantitative information about pixel temperatures like the raster data do, but they do contain spatial information about relative surface temperature variations within each thermal area and can be used to incrementally focus in on the warmer parts of each thermal area.

ASTER-based thermal pixel polygons were created from ASTER TIR pixels using ENVI ${ }^{\circledR}$ software processing tools by Exelis, Inc. First the "region of interest" tool was used to select the pixels in each temperature threshold level. Then a "class image" was created from each region of interest (this is a binary classification image where the "region of interest" pixels are assigned a value of one and all other pixels assigned a value of zero). Then the ENVI ${ }^{\circledR}$ "classification to vector" tool was used to export the class image into an ENVI ${ }^{\circledR}$ vector file, which was then exported as an Esri

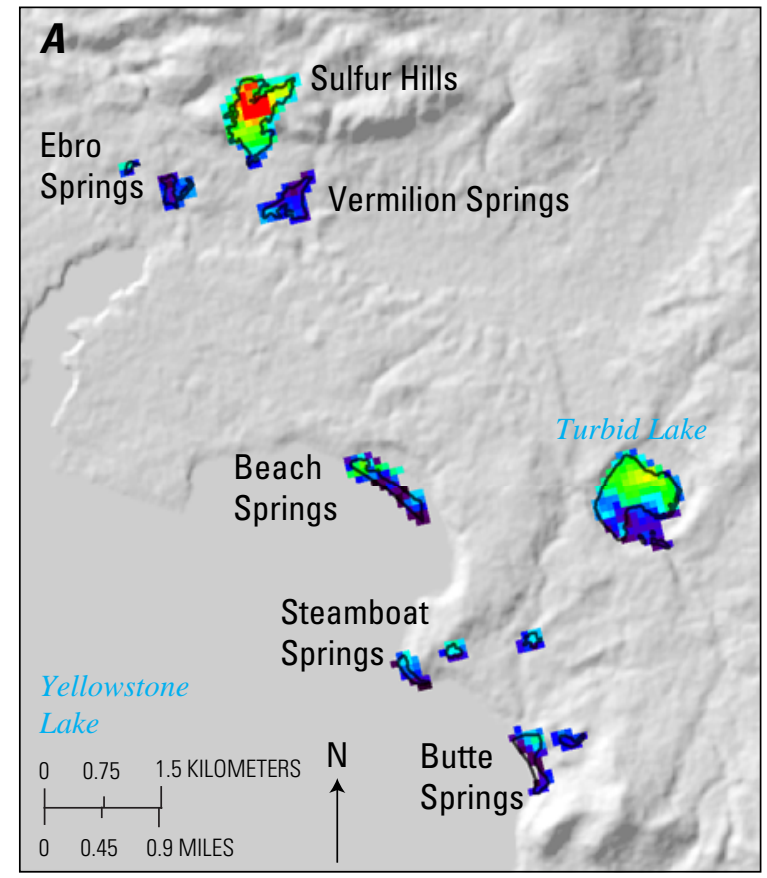

Temperature Anomaly Map

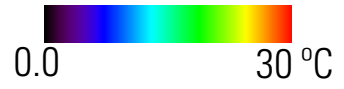

\section{Sulfur Hills}

Max Temperature Anomaly: $43^{\circ} \mathrm{C}$

Turbid Lake

Max Temperature Anomaly: $21^{\circ} \mathrm{C}$ shapefile. ASTER warm pixels from each of the four image acquisition dates were combined. They were then divided into individual polygon shapefiles for each of the four temperature threshold levels. Unlike the TAPG polygons, the ASTER-based thermal pixel polygons at the greater-thanbackground-mean level tend to have buffer zones around the TAPG polygons that are about 1 pixel in size.

\section{Datasets Not Included in this Release}

The following vector datasets are not included in this version of the report: Lakes, Rivers, and Roads in Yellowstone. These data are available from the Yellowstone Center for Resources online GIS database (https://irma.nps. gov/App/Reference/Search). The U.S. Geological Survey (USGS) provides background image data (such as the 2006 NAIP imagery), and digital elevation model data at EarthExplorer (http://earthexplorer.usgs.gov).

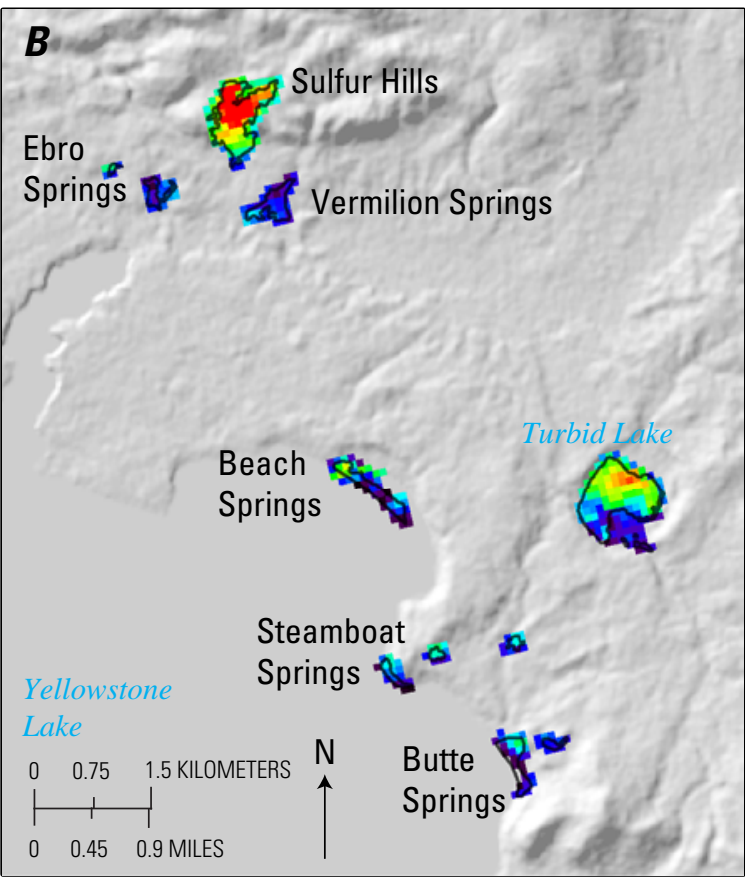

\section{Radiant Emittance Anomaly Map}

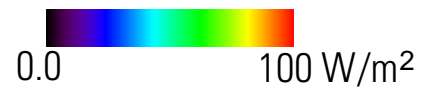

\section{Sulfur Hills \\ Max Radiant Emittance Anomaly: $210 \mathrm{~W} / \mathrm{m}^{2}$ \\ Geothermal Radiant Flux: 54 MW \\ Turbid Lake \\ Max Radiant Emittance Anomaly: $95 \mathrm{~W} / \mathrm{m}^{2}$ \\ Geothermal Radiant Flux: 36 MW}

Figure 9. Maps showing thermal anomalies in the region around Sulfur Hills and Turbid Lake. $A$, Temperature anomaly map. $B$, Radiant emittance anomaly map. Both are thermal infrared-based anomaly maps derived from Advanced Spaceborne Thermal Emission and Reflection Radiometer data acquired on January 28, 2010. The background is a hillshade image from the Shuttle Radar Topography Mission digital elevation model. The maps are centered on $44.55^{\circ} \mathrm{N} ., 110.30^{\circ} \mathrm{W}$. 


\section{References Cited}

Bergfeld, D., Evans, W.C., Lowenstern, J.B., and Hurwitz, S., 2012, Carbon dioxide and hydrogen sulfide degassing and cryptic thermal input to Brimstone Basin, Yellowstone National Park, Wyoming: Chemical Geology, v. 330-331, p. 233-243.

Boyd, R.W., 1983, Radiometry and the detection of optical radiation: New York, Wiley, 272 p.

Christiansen, R.L., 2001, The Quaternary and Pliocene Yellowstone Plateau volcanic field of Wyoming, Idaho, and Montana: U.S. Geological Survey Professional Paper 729-G, 145 p., 3 pls. [Also available at http://pubs.usgs. gov/pp/pp729g/.]

Christiansen, R.L., Lowenstern, J.B., Smith, R.B., Heasler, H., Morgan, L.A., Nathenson, M., Mastin, L.G., Muffler, L.J.P., and Robinson, J.E., 2007, Preliminary assessment of volcanic and hydrothermal hazards in Yellowstone National Park and vicinity: U.S. Geological Survey Open-File Report 2007-1071, 94 p. [Also available at http://pubs.usgs.gov/ of/2007/1071/.]

Ellis, A.J., and Wilson, S.H., 1955, The Heat from the Wairakei-Taupo thermal region calculated from the chloride output: New Zealand Journal of Science and Technology, v. 36, p. 622-631.

Farrell, J., Husen, S., and Smith, R.B., 2009, Earthquake swarm and $b$-value characterization of the Yellowstone volcano-tectonic system: Journal of Volcanology and Geothermal Research, v. 188, p. 260-276.

Fournier, R.O., 1979, Geochemical and hydrologic considerations and the use of enthalpy-chloride diagrams in the prediction of underground conditions in hot-spring systems: Journal of Volcanology and Geothermal Research, v. 5, p. 1-16.

Fournier, R.O., 1989, Geochemistry and dynamics of the Yellowstone National Park hydrothermal system: Annual Review of Earth and Planetary Sciences, v. 17, p. 13-53.

Fournier, R.O., White, D.E., and Truesdell, A.H., 1976, Convective heat flow in Yellowstone National Park in Proceedings of the U.N. Symposium on the Development and Use of Geothermal Resources, 2d, San Francisco, May 20-29, 1975: Washington, D.C., U.S. Government Printing Office, v. 1, p. 731-739.

Friedman, I., and Norton, D.R., 2007, Is Yellowstone losing its steam? - Chloride flux out of Yellowstone National Park, in Morgan, L.A., (ed.), Integrated geoscience studies in the greater Yellowstone area-Volcanic, hydrothermal and tectonic processes in the Yellowstone geoecosystem: U.S. Geological Survey Professional Paper 1717, p. 271-298.
Gillespie, A., Rokugawa, S., Matsunaga, T., Cothern, J.S., Hook, S., and Kahle, A.B., 1998, A temperature and emissivity separation algorithm for Advanced Spaceborne Thermal Emission and Reflection Radiometer (ASTER) images: IEEE Transactions on Geoscience and Remote Sensing, v. 36, no. 4, p. 1113-1126.

Heasler, H.P., Jaworowski, C., and Foley, D., 2009, Geothermal systems and monitoring hydrothermal features in Young, Rob, and Norby, Lisa, eds., Geological Monitoring: Boulder, Colorado, Geological Society of America, p. 105-140.

Hulley, G.C., and Hook, S.J., 2009, The North American ASTER land surface emissivity database (NAALSED) Version 2.0: Remote Sensing of Environment, v. 113, v. 9, p. 1967-1975.

Hurwitz, S., Harris, R.N., Werner, C.A., and Murphy, F., 2012, Heat flow in vapor dominated areas of the Yellowstone Plateau volcanic field-Implications for the thermal budget of the Yellowstone caldera: Journal of Geophysical Research, v. 117, no. B10207. [Also available at http:// dx.doi.org/10.1029/2012JB009463.]

Hurwitz, S., Lowenstern, J.B., and Heasler, H., 2007, Spatial and temporal geochemical trends in the hydrothermal system of Yellowstone National Park-Inferences from river solute fluxes: Journal of Volcanology and Geothermal Research, v. 162, p. 149-171.

Ingebritsen, S.E., Galloway, D.L., Colvard, E.M., Sorey, M.L., and Mariner, R.H., 2001, Time-variation of hydrothermal discharge at selected sites in the western United StatesImplications for monitoring: Journal of Volcanology and Geothermal Research, v. 111, p. 1-23.

Jaworowski, C., Heasler, H.P., Neale, C.M.U., and Sivarajan, S., 2010, Using thermal infrared imagery and LiDAR in Yellowstone geyser basins: Yellowstone Science, v. 18, no. 1, p. 8-19.

Lowenstern, J.B., and Hurwitz, S., 2008, Monitoring a supervolcano in repose- - Heat and volatile flux at the Yellowstone caldera: Elements, v. 4, no. 1, p. 35-40.

Lowenstern, J.B., Smith, R.B., and Hill, D.P., 2006, Monitoring super-volcanoes - geophysical and geochemical signals at Yellowstone and other large caldera systems: Philosophical Transactions of the Royal Society A, v. 364, no. 1845, p. 2055-2072.

Montana State University, [2007], Thermal Inventory Geodatabase: Yellowstone National Park Research Coordination Network database, accessed 12/1/2008, at http://www.rcn.montana.edu/resources/features/features. aspx?nav=11. [Database moved by time of publication; Geothermal Site Database accessed May 16, 2014, at http://www.rcn.montana.edu/Features/Search.aspx; search interface changed so that search parameters are different.] 
Morgan, L.A., Shanks, W.C., III, and Pierce, K.L., 2009, Hydrothermal processes above the Yellowstone magma chamber-Large hydrothermal systems and large hydrothermal explosions: Geological Society of America Special Paper 459, p. 1-95. [Also available at http://dx.doi.org/10.1130/2009.2459(01).]

National Park Service, 2011, [Spatial Analysis Center, Yellowstone National Park: All Rivers in Yellowstone National Park, All Roads in Yellowstone National Park, Landforms and Associated Surficial Materials of Yellowstone National Park], Integrated Resource Management Applications (IRMA) Portal, accessed 1/1/2010, at https://irma.nps.gov/App/Reference/Search.

Neale, C.M.U., Sivarajan, S., Masih, A., Jaworowski, C., and Heasler, H., 2011, Estimating heat flow of thermal features in Yellowstone National Park Using airborne thermal infrared remote sensing [abs.]: American Geophysical Union, Fall Meeting 2011 Abstracts, abstract no. H51C-1225, available at http://abstractsearch.agu.org/meetings/2011/FM/sections/H/ sessions/H51C/abstracts/H51C-1225.html.

Nordstrom, D.K., McCleskey, R.B., Ball, J.W., 2009, Sulfur geochemistry of hydrothermal waters in Yellowstone National Park-IV acid-sulfate waters: Applied Geochemistry, v. 24, no. 2, p. 191-207.

Palluconi, F., Hoover, G., Alley, R., Jentoft-Nilsen, M., and Thompson, T., 1999, An atmospheric correction method for ASTER thermal radiometry over land (revision 3): NASA's Earth Observing System Algorithm Theoretical Basis Document ATBD-AST-09T, $27 \mathrm{p}$.

Pollack, H.N., Hurter, S.J., and Johnson, J.R., 1993, Heat flow from the Earth's interior-Analysis of the global data set: Reviews of Geophysics, v. 31, no. 3, p. 267-280.

Ramsey, M., Dehn, J., Wessels, R., Byrnes, J., Duda, K., Maldonado, L., and Dwyer, J., 2004, The ASTER emergency scheduling system-A new project linking near-real-time satellite monitoring of disasters to the acquisition of highresolution remote sensing data [abs.]: American Geophysical Union, Fall Meeting 2004 Abstracts, abstract no. SF23A-0026.

Savage, S.L., Lawrence, R.L., Custer, S.G., Jewett, J.T., Powell, S.L., and Shaw, J.A., 2010, Review of alternative methods for estimating terrestrial emittance and geothermal heat flux for Yellowstone National Park using Landsat imagery: GIScience and Remote Sensing, v. 47, no. 4, p. 460-479.

Savage, S.L., Lawrence, R.L., Custer, S.G., Jewett, J.T., Powell, S.L., and Shaw, J.A., 2012, Analyzing change in Yellowstone's terrestrial emittance with Landsat imagery: GIScience and Remote Sensing, v. 49, no. 3, p. 317-345.

Smith, R.B., and Braile, L.W., 1994, The Yellowstone hotspot: Journal of Volcanology and Geothermal Research, v. 61, p. 121-187.
Smith, R.B., Jordan, M., Steinberger, B., Puskas, C.M., Farrell, J., Waite, G.P., Husen, S., Chang, W.L., and O'Connell, R., 2009, Geodynamics of the Yellowstone hotspot and mantle plume - seismic and GPS imaging, kinematics, and mantle flow: Journal of Volcanology and Geothermal Research, v. 188, p. 26-56.

Thome, K., Palluconi, F., Takashima, T., and Masuda, K., 1998, Atmospheric correction of ASTER: IEEE Transactions on Geoscience and Remote Sensing, v. 36, no. 4, p. 1199-1211.

Vaughan, R.G., Keszthelyi, L.P., Heasler, H., Jaworowski, C., Lowenstern, J.B., and Schneider, D.J., 2009, Thermal infrared remote sensing of the Yellowstone geothermal system [abs.]: American Geophysical Union, Fall Meeting 2009 Abstracts, abstract no. V21B-1993, available at http:// abstractsearch.agu.org/meetings/2009/FM/sections/V/ sessions/V21B/abstracts/V21B-1993.html.]

Vaughan, R.G., Keszthelyi, L.P., Lowenstern, J.B., Jaworowski, C., and Heasler, H., 2012, Use of ASTER and MODIS thermal infrared data to quantify heat flow and hydrothermal change at Yellowstone National Park: Journal of Volcanology and Geothermal Research, v. 233-234, p. $72-89$.

Watson, F.G.R., Lockwood, R.E., Newman, W.B., Anderson, T.N., and Garrott, R.A., 2008, Development and comparison of Landsat radiometric and snowpack model inversion techniques for estimating geothermal heat flux: Remote Sensing of Environment, v. 112, no. 2, p. 471-481.

Werner, C., Hurwitz, S., Evans, W.C., Lowenstern, J.B., Bergfeld, D., Heasler, H., Jaworowski, C., and Hunt, A., 2008, Volatile emissions and gas geochemistry of Hot Spring Basin, Yellowstone National Park, USA: Journal of Volcanology and Geothermal Research, v. 178, no. 4, p. 751-762.

White, D.E., Fournier, R.O., Muffler, L.J.P., and Truesdell, A.H., 1975, Physical results of research drilling in thermal areas of Yellowstone National Park, Wyoming: U.S. Geological Survey Professional Paper 892, 70 p.

Yamaguchi, Y., Kahle, A.B., Tsu, H., Kawakami, T., Pniel, M., 1998, Overview of Advanced Spaceborne Thermal Emission and Reflection Radiometer (ASTER): IEEE Transactions on Geoscience and Remote Sensing, v. 36, no. 4, p. 1062-1071. 


\section{Appendix}

Appendix 1 contains a table with the names and characteristics of Yellowstone's thermal areas. Most thermal areas mapped in the initial TAPG had official names, but some did not (they were labeled "NA"). Areas that had an official name, but that did not appear to be thermally active were not changed, except to be classified as inactive. Unofficial names (descriptive placeholders) were given to the unlabeled thermal areas based on their locations near other named features, like creeks. Three new fields in the table were added to differentiate between various thermal areas characteristics: (1) Chem_Type (chemistry type), which differentiates between acid-sulfate and neutral-chloride thermal areas, and also labels features like thermal drainages; (2) Th_Active, which labels the thermal areas as thermally emissive, inactive, or cold degassing; and (3) TIG_pts, which labels the thermal areas that contain Research Coordination Network Thermal Inventory Geodatabase (TIG) points.

Table A1. Names and characteristics of Yellowstone's thermal areas.

\begin{tabular}{|c|c|c|c|c|}
\hline Name & Area $\left(\mathrm{m}^{2}\right)$ & Chemistry type & Thermal activity & TIG points \\
\hline Amphitheater Springs North* & 19,896 & Unknown & Thermally emissive & TIG points \\
\hline Apollinaris Spring & 29,232 & Unknown & Inactive? & \\
\hline Artist Point Thermal Area & 998,042 & Acid Sulfate? & Thermally emissive & \\
\hline Beach Springs & 146,582 & Unknown & Thermally emissive & TIG points \\
\hline Bear Creek Thermal Area (outside Park) & 47,699 & Unknown & Unknown & \\
\hline Bechler Meadows Thermal Area & 88,715 & Unknown & Inactive? & \\
\hline Boiling River & 6,059 & Unknown & Thermally emissive & TIG points \\
\hline Boundary Creek Thermal Area & 194,612 & Unknown & Thermally emissive & TIG points \\
\hline Brimstone Basin & $2,477,888$ & Acid Sulfate? & Cold degassing & \\
\hline Broad Creek Thermal Area & 537,875 & Acid Sulfate & Thermally emissive & TIG points \\
\hline Butte Springs & 157,719 & Acid Sulfate? & Thermally emissive & TIG points \\
\hline Calcite Springs & 39,853 & Unknown & Thermally emissive? & \\
\hline Cottongrass Creek Thermal Area & 40,523 & Unknown & Inactive? & TIG points \\
\hline Crater Hills East Thermal Area* & 13,470 & Unknown & Inactive? & \\
\hline Crater Hills Thermal Area & 330,649 & Acid Sulfate & Thermally emissive & TIG points \\
\hline Crayfish Thermal Area & 225,372 & Unknown & Thermally emissive & TIG points \\
\hline Crystal Spring* & 92,006 & Unknown & Inactive? & \\
\hline
\end{tabular}


Table A1. Names and characteristics of Yellowstone's thermal areas.-Continued

\begin{tabular}{|c|c|c|c|c|}
\hline Name & Area $\left(\mathrm{m}^{2}\right)$ & Chemistry type & Thermal activity & TIG points \\
\hline Devil's Den East Thermal Area* & 95,782 & Unknown & Thermally emissive? & \\
\hline Devil's Inkstand Thermal Area & 35,704 & Acid Sulfate? & Thermally emissive & \\
\hline Dundunda Falls Thermal Area & 11,584 & Unknown & Inactive? & \\
\hline Ebro Springs East* & 62,864 & Unknown & Inactive? & \\
\hline Fairyland Basin & 36,564 & Neutral Chloride? & Thermally emissive & TIG points \\
\hline Falls River East Thermal Area* & 74,409 & Unknown & Thermally emissive & TIG points \\
\hline Forest Springs & 644,626 & Acid Sulfate & Thermally emissive & TIG points \\
\hline Frying Pan Springs & 7,351 & Acid Sulfate & Thermally emissive & TIG points \\
\hline Gibbon Geyser Basin & $1,874,455$ & Acid Sulfate & Thermally emissive & TIG points \\
\hline Glen Africa Basin & 225,603 & Neutral Chloride & Thermally emissive & TIG points \\
\hline Grebe Pit (Solfatara Plateau) Thermal Area* & 104,389 & Acid Sulfate & Thermally emissive & TIG points \\
\hline Heart Lake Geyser Basin & 815,425 & Acid Sulfate & Thermally emissive & TIG points \\
\hline Joseph's Coat Springs & 904,171 & Acid Sulfate & Thermally emissive & TIG points \\
\hline La Duke Hot Springs (outside Park) & 2,365 & Unknown & Unknown & \\
\hline Lake of the Woods Thermal Area* & 106,159 & Unknown & Inactive? & \\
\hline Lewis Lake South Thermal Area* & 7,067 & Unknown & Thermally emissive & TIG points \\
\hline Lewis Lake Thermal Area & 683,453 & Neutral Chloride & Thermally emissive & TIG points \\
\hline Lewis Lake West Thermal Area* & 402,645 & Unknown & Thermally emissive & \\
\hline Little Saddle Mtn Quad Thermal Area* & 92,524 & Unknown & Inactive? & \\
\hline Lone Star Geyser Basin Area & $1,109,110$ & Neutral Chloride & Thermally emissive & TIG points \\
\hline Lower Geyser Basin & $14,580,366$ & Neutral Chloride & Thermally emissive & TIG points \\
\hline Mammoth Hot Springs & 879,332 & Neutral Chloride & Thermally emissive & TIG points \\
\hline Mammoth Hot Springs West* & 282,452 & Neutral Chloride? & Inactive? & \\
\hline
\end{tabular}


Table A1. Names and characteristics of Yellowstone's thermal areas.-Continued

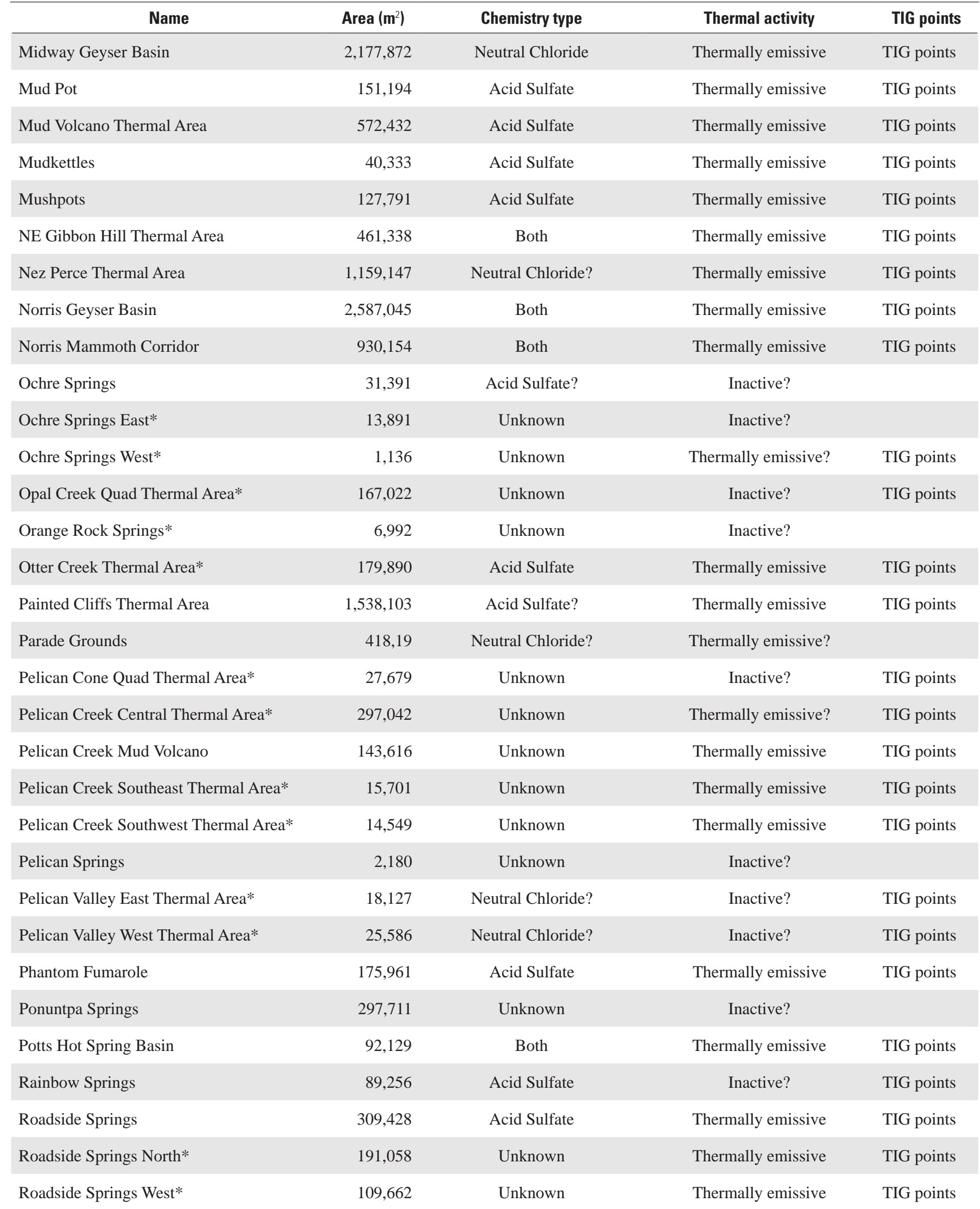


Table A1. Names and characteristics of Yellowstone's thermal areas.-Continued

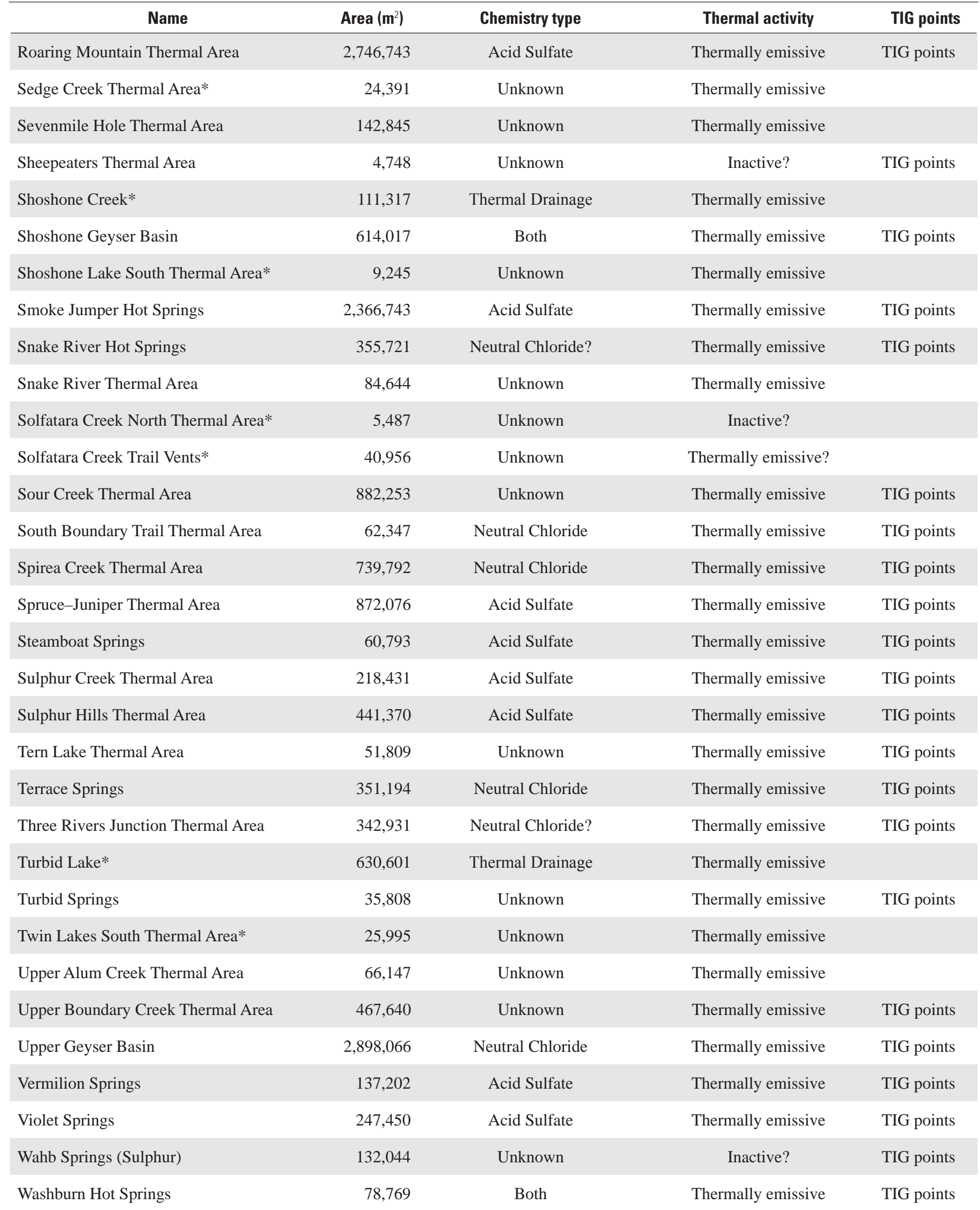




\section{Provisional Maps of Thermal Areas in Yellowstone National Park}

Table A1. Names and characteristics of Yellowstone's thermal areas.-Continued

\begin{tabular}{lccc}
\hline \multicolumn{1}{c}{ Name } & Area $\left(\mathbf{m}^{2}\right)$ & Chemistry type & Thermal activity \\
\hline West Astringent Creek Thermal Area & 905,088 & Unknown & Thermally emissive \\
\hline West Juniper Creek Thermal Area & $1,409,778$ & Unknown & Thermally emissive \\
\hline West Nymph Creek Thermal Area & 64,021 & Both & Thermally emissive \\
\hline West Thumb Geyser Basin & 124,218 & Neutral Chloride & Thermally emissive \\
\hline Whiterock Springs & 39,659 & Unknown & Thermally emissive? \\
\hline
\end{tabular}

${ }^{*}$ Unofficial name. 
Menlo Park Publishing Service Center, California

Manuscript approved for publication on July 14, 2014

Edited by Regan Austin

Design and layout by Cory Hurd 
